BANCA D'ITALIA

E U R O S I S T E M A

Questioni di Economia e Finanza

(Occasional Papers)

The evolution of inequality and social cohesion in Europe: 1957-2017

by Francesco Vercelli

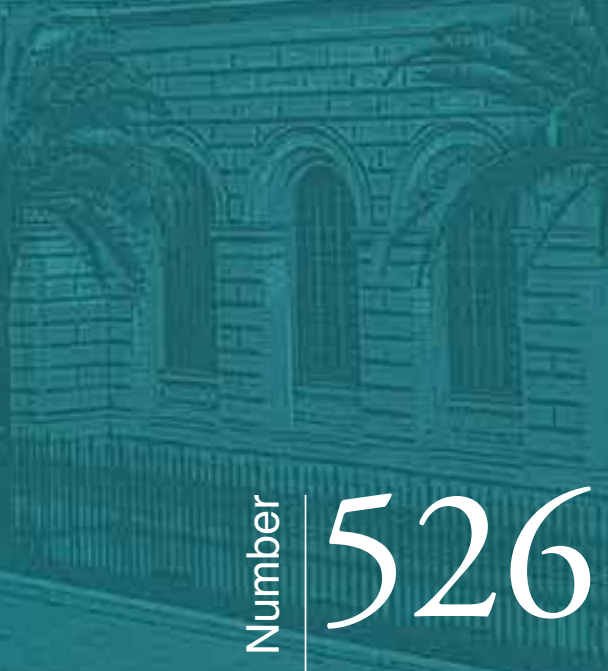



13 BANCA D'ITALIA

E U ROS I S T E M A

\section{Questioni di Economia e Finanza}

(Occasional Papers)

The evolution of inequality and social cohesion in Europe: 1957-2017

by Francesco Vercelli

Number 526 - November 2019 
The series Occasional Papers presents studies and documents on issues pertaining to the institutional tasks of the Bank of Italy and the Eurosystem. The Occasional Papers appear alongside the Working Papers series which are specifically aimed at providing original contributions to economic research.

The Occasional Papers include studies conducted within the Bank of Italy, sometimes in cooperation with the Eurosystem or other institutions. The views expressed in the studies are those of the authors and do not involve the responsibility of the institutions to which they belong.

The series is available online at www.bancaditalia.it.

ISSN $1972-6627$ (print)

ISSN 1972-6643 (online)

Printed by the Printing and Publishing Division of the Bank of Italy 


\title{
THE EVOLUTION OF INEQUALITY AND SOCIAL COHESION \\ IN EUROPE: 1957-2017
}

\author{
by Francesco Vercelli*
}

\begin{abstract}
Our study finds that income inequality among EU-15 citizens decreased remarkably from 1957 to 2017, with the Gini coefficient dropping by nearly 30 per cent. The process was very rapid until the mid-1980s. It then slowed gradually, to the point that inequality started rising at the beginning of the 2000s. The estimates of European income distribution and the inequality measures we compute are based on the method proposed by Sala-i-Martin (2006). This methodology overcomes the problem of the limited availability of long-term survey data on income by using income shares from the World Income Inequality Database.
\end{abstract}

JEL Classification:. D3, N34, O15.

Keywords: Income inequality, European integration, Gini coefficient.

DOI: $10.32057 / 0 . Q E F .2019 .526$

\section{Contents}

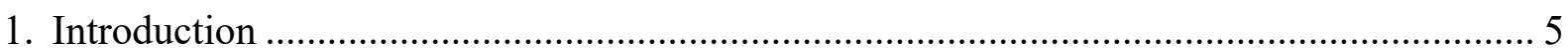

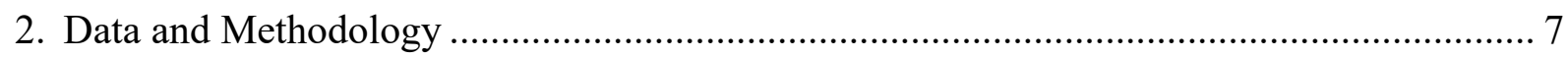

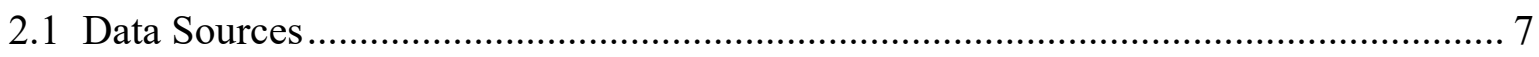

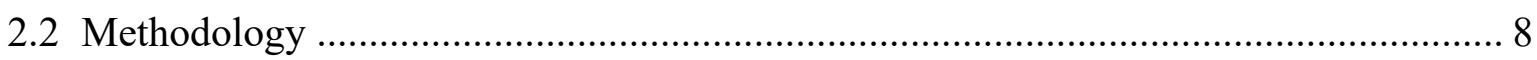

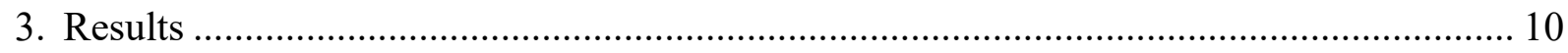

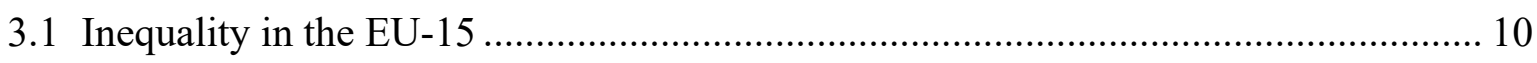

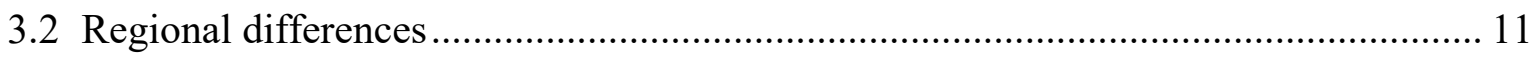

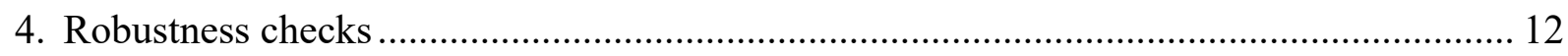

4.1 Shortcomings of the integration-of-kernels method................................................... 12

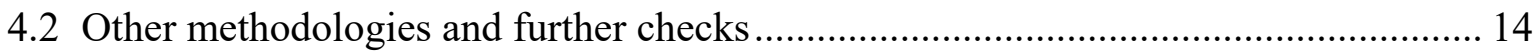

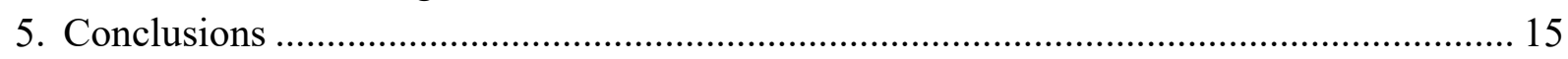

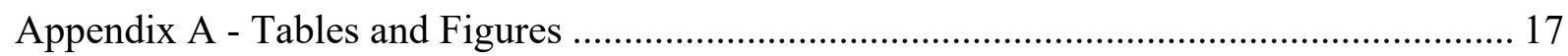

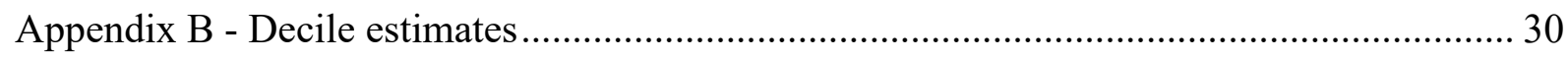

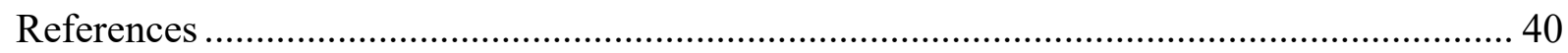

\footnotetext{
* Bank of Italy, Economic Research and International Relations.
} 



\section{$1 \quad$ Introduction $^{1}$}

The European Union Treaty claims that economic and social cohesion among the member states is one of the main objectives of the Community (art. 2). From 2014 to $2020,34 \%$ of the total EU budget (€371.4 billion) is devoted to Economic, social and territorial cohesion policies (European Commission, 2018). However, has the EU effectively achieved a higher level of social cohesion among its citizens? Using the method proposed by Sala-i-Martin (2006), we find that the answer is yes: the Gini coefficient has decreased approximately by $30 \%$ since 1957, the year of the Treaty of Rome.

Social cohesion has always been linked to economic convergence among regions. The Treaty of Rome (1957) established the creation of the European Social Fund and the European Investment Bank with regional development aims. Then, in the 1960s a new General Direction (DG XVI) of the Commission was created with regional responsibilities, strengthened in 1975 by the European Regional Development Fund. This focus on regional issues has obscured the importance of disparities in income among European citizens, disregarding their national citizenships. However, the unification process suggests that we consider the European Union as a unique country, at least from an economic perspective. Therefore it is crucial to have not only estimates of inequality measures of single member states but also indices of social cohesion in the Community as a whole (Social Situation Observatory, 2012).

The difference between regional convergence and inequality among citizens has been discussed thoroughly in the literature. Atkinson (1975) distinguishes between the international distribution of income, that is "the differences between countries in terms of average per capita incomes", and the world distribution of income, that is "the distribution of income among all people of the world". The former is less concentrated than the latter, since it does not consider the dispersion within each single country (Sala-i-Martin, 2006). For this reason we should keep in mind what concept of inequality we are analyzing.

Many studies conducted on the basis of Solow's model derive estimates of convergence among countries. Some analyze absolute convergence assuming that all the countries share the same steady state in the long run; others investigate relative convergence, allowing for different steady states depending on economic, demographic and institutional characteristics. In these studies every country in the world has the same weight. Then, in order to overcome this oversimplification, Schultz (1998) weighs every country by its population. However, he assumes that all the inhabitants of a country have the same income level.

In order to obtain the world income distribution we should have comparable survey data on income for every country and every year. Milanovic (2003) derives the world income distribution relying only on household surveys but restricts the estimates to 1988 and 1993 because of the shortage of data.

Eventually, Sala-i-Martin (2006) introduces a methodology to estimate the world

\footnotetext{
${ }^{1}$ I thank Andrea Brandolini, Pietro Garibaldi, Camelia Minoiu and Filippo Taddei for their support and suggestions. This is a revised version of an earlier paper: Vercelli F., 2011, "The Evolution of Inequality and Social Cohesion in Europe", mimeo.
} 
income distribution, taking into account the income dispersion within countries. This article uses data provided by the World Bank (Deininger and Squire, 1996) that have been later included in the World Income Inequality Database (WIID). This database reports the income percentages (income shares) owned by different income classes of the population. Although there are no data for the entire period covered by Sala-i-Martin's article (1970 to 2000), he observes that income shares have smooth time trends and so he estimates the missing values with a linear model. Assuming that GDP is distributed among citizens as income in household surveys, he assigns an income level to every quintile of each country between 1970 and 2000 only using data on population and GDP (PPP-adjusted). Then he applies a kernel density function to attribute a particular level of income to every citizen, and finally integrate annual country distributions to obtain the income distribution among all the inhabitants of the world.

Sala-i-Martin's methodology has serious limitations. In particular, the poor quality of data is a concern; the combination of GDP and income surveys is controversial and the use of kernel density estimation is highly questionable in this framework. However this approach is still very interesting because it is a simple way for estimating the evolution of inequality and poverty in the world when there is not direct access to micro surveys. In addition this methodology is also applicable to supranational entities, such as the European Union.

There are several studies on income inequality among European citizens. Brandolini (2007) derives the EU-25 income distribution in 2000 by collecting household data around 2000 from the Luxembourg Income Surveys. Fredriksen (2012) exploits OECD data on average disposable income per decile to obtain estimates of income inequality in some benchmark years between the mid-1980s and 2008. Brandolini and Rosolia (2019) analyse income distribution in EU-28 from 2005 to 2015 using EU-SILC data and highlight the importance of obtaining EU-wide measures of inequality and poverty. Blanchet et al. (2019) investigate income distribution in 38 European countries from 1980 to 2017 by developing a computational intensive methodology that combine surveys, tax data and national accounts.

Our study evaluate the process of economic cohesion in the EU-15, from the Treaty of Rome in 1957 up to 2017. We apply the methodology suggested by Salai-Martin - and some variants of it - which is suitable for analysing such a historical horizon. In particular, we exploit data from the World Income Inequality Database which reports income shares also for the 1950s for many of the member states. ${ }^{2}$ The measures we compute refer to all the EU-15 member states, disregarding the year they joined the European Union (or the European Economic Community). Indeed, we are not interested in the relationship between inequality and integration but in income convergence in a particular group of countries. Of course, since the period of analysis ends in 2017, the United Kingdom is included.

We obtain important results, showing that European incomes have effectively converged from 1957 to 2017. The process has been more remarkable for the founding

\footnotetext{
${ }^{2}$ Long series of data on income distribution for many European countries are also available in "The World Top Income Database" (Alvaredo et al., 2012). Nonetheless, this database concentrates only on top income shares. See Atkinson et al. (2011) on top incomes in a historical perspective.
} 
countries of the European Economic Community, with a central role played by France and Germany. Actually, the convergence process has not been linear. It was rapid before the mid-1980s, then slowed down and reversed at the beginning of the 2000s: inequality keeps rising.

Section 2 shows the data and how we apply the kernel of kernels method. Section 3 reports the results for the European Union; then it shows the inequality patterns that emerge by dividing the 15 countries into four regional macro areas (Nordic countries, English-Speaking countries, Central Europe, Southern Europe) and in the founding member states. Section 4 checks the reliability of the results by using other methodologies. Finally, Section 5 presents the conclusions.

\section{Data and Methodology}

\subsection{Data Sources}

Sala-i-Martin (2006) proposes a methodology - which we define integration-of-kernels method $^{3}$ - to obtain income distributions among citizens of supranational entities without direct access to national household surveys. This methodology requires the following national data for every year:

- Population.

- GDP per capita in real terms and in constant Purchasing Power Parity.

- Income shares.

Data on population and real GDP per capita in PPP for the years 1957 to 2017 are available in the Penn World Table (PWT). ${ }^{4}$

UNU/WIDER (2018) provides a secondary dataset, the World Income Inequality Database (WIID), that collects information about income and inequality from many income surveys. The first version of WIID was published in 2000, starting from the original database from Deininger and Squire (1996). Since then several versions have been released, improving the database in terms of coverage, quality and documentation. ${ }^{5}$ Since WIID provides decile estimations for the 15 countries of our study, we prefer these to the quintiles used by Sala-i-Martin. There are two arising issues. First, should we keep all the available observations, even if there are inconsistencies due to different sources? Second, what should we do when WIID provides multiple observations for the same country and the same year?

The first issue relates to the availability of data. Since there are generally few observations, we decide to accept all those provided by WIID. This study focuses on the 1957-2017 period but we also use observations up to 1948 in order to better

\footnotetext{
${ }^{3}$ The methodology in Sala-i-Martin (2006) is defined in Sala-i-Martin (2002) as kernel of kernels. However, this expression may be misleading because the method actually consists in integrating annual country distributions estimated through kernel density.

${ }^{4}$ Results are similar using data from the Maddison Project Database (Bolt et al., 2018).

${ }^{5}$ In this paper we use version 3.4 of WIID.
} 
estimate the missing shares. For the 1948-2017 period covered by WIID there are some countries with few observations and long periods without data; this problem concerns mainly Greece, Portugal, Austria, Luxembourg, Belgium and Ireland (see Table 1). However, all these countries account only for about $15 \%$ of the total population. Generally there are more observations from the last two decades and fewer from the 1950s and 1960s. In particular Austria, Belgium, Ireland, Portugal and Spain do not have information from micro surveys in the 1950s. The decision to keep all the available observations matters because there can be inconsistencies due to different statistical sources. Nevertheless, it is difficult to distinguish between a real change in income shares and a change due to a variation in statistical sources. So we keep all the observations that WIID provides, keeping in mind that using different sources may produce more volatile estimates.

The second problem is how to choose among multiple observations for the same country in a given year. WIID provides for each observation a quality rating: low, average, high, not known. Clearly, in case of multiple observations for the same country in a given year, we select the one with the higher quality rating.

There is a variety of sources in WIID, even within the same country and sometimes for the same year. The criterion we use to choose is the continuity of the source; so we prefer an observation whose source is available in the previous or following years. We favor continuity of sources within the same country; for example from 1995 to 2001 the same source is available for all the European countries (except Denmark) but for the United Kingdom we decide to use another source (Goodman and Shephard, 2002) that covers all the 1961-2002 period.

We use income share observations based on households' net income, since we are interested in effective inequality among European citizens. However, since this kind of information is not always available, we also keep few observations that are based either on another concept (monetary disposable, gross income) or on another income sharing unit (tax units, family). We prefer those observations that use an equivalence scale instead of the household per capita income.

Finally, income shares after 2008 are directly obtained from Eurostat, which compute them from the EU-SILC database. Data on income shares for Finland, Sweden and Denmark between 1987 and 2007 are integrated using more detailed information provided by the National statistical institutes. ${ }^{6}$

\section{$2.2 \quad$ Methodology}

WIID reports only few observations for the income shares because there is not an income survey for each country and for each year. A possible solution is to estimate inequality measures at different intervals of time (see Milanovic, 2003). For example, to derive the income distribution around 2000, if a country has no observation in WIID for that year, we could keep the closest available in the 1998-2002 period. Generally in the literature five-year intervals are used but this is not possible in

\footnotetext{
${ }^{6}$ These National statistical institutes provide series of income shares based on household equivalent disposable income excluding capital gains, which is also the definition followed in Eurostat data. We thank Andrea Brandolini for indicating these data.
} 
studying the UE-15 for over half a century since the available observations are not sufficient. Using ten-year intervals would be questionable since it is too strong to assume that income shares are constant for such a long time.

For this reason, as in Sala-i-Martin (2006), we estimate the missing income shares. Sala-i-Martin observes that quintile income shares follow smooth time trends and argues that can be well approximated with linear regressions. This assumption has been widely criticized, based on the evidence on U-shaped inequality patterns (see among others Hong et al., 2019). In our study the assumption would deliver even poorer approximations because European deciles follow smooth but more complex paths than quintiles. A way for capturing these smooth but non-linear patterns is to apply fractional polynomials techniques. Income shares are regressed on a fractional polynomial in time; an algorithm automatically choose the fractional polynomial that produces the best fit. ${ }^{7}$ Missing income shares are then obtained by interpolating in-sample predictions. ${ }^{8}$ Appendix B reports figures on the estimated values for each decile and country.

Now we need to assign a mean income to each decile of the population. Let $\hat{s}_{i k t}$ be the original or predicted income share of country $i$, decile $k$ and year $t, N_{i t}$ the population and $y_{i t}$ the real GDP per capita in PPP. The mean income of decile $k$ is given by dividing the share of GDP by the number of people of that decile. Letting $Y_{i t}$ be real GDP in PPP of country $i$ and year $t$, we can write:

$$
\hat{\mu}_{i k t}=\frac{\hat{s}_{i k t} \cdot Y_{i t}}{\frac{N_{i t}}{10}}=10 \cdot \hat{s}_{i k t} \cdot y_{i t}
$$

This multiplication delivers the mean income of each decile, of each country and of each year between 1957 and 2017. We are assuming that GDP is distributed as income in household surveys and that each individual has the same level of income within a decile. ${ }^{9}$

At this point we can apply the integration-of-kernels methodology proposed by Sala-i-Martin to assign a specific income to every citizen. For each country and year, we evaluate a Gaussian kernel density function at every log income level, using the optimal bandwidth of Silverman; the log transformation reduces a bias due to the boundedness of the support at zero (Minoiu and Reddy, 2008). Indeed, the mass close to zero is underestimated and the log-transformation increases the number of observations on the left of the distribution. In this way we can compensate for the boundary bias.

Multiplying the estimated densities by the total population of that country in a given year, the area below the function becomes the total population. By integrating this function between two near points in $\log$ terms we find the estimated number

\footnotetext{
${ }^{7}$ The maximum degree of the fractional polynomial is set to 3 but the estimates are robust using 2 or 4 .

${ }^{8}$ We obtain estimates for each decile without worrying about the adding-up constraints (the fact the sum of the income shares must be equal to one for each country). We then rescale the estimated deciles so that they sum up to one. This is a small adjustment: the fifth deciles obtained by difference are not statistically different from those estimated.

${ }^{9}$ Inequality is computed in terms of individuals and not of households.
} 
of people at a particular level of income. Eventually, by summing up the national distributions of income, we get the European one.

\section{$3 \quad$ Results}

\subsection{Inequality in the EU-15}

Figure 1 presents the distributions of income in 1957 and 2017 for the four most populous countries: France, Germany, Italy and the United Kingdom. It is possible to observe that the distributions are more similar between countries in 2017 than in 1957.

Now we are ready to compute the following inequality measures:

- The percentile ratio between the 90th percentile and the 10th (p90/p10).

- The percentile ratio between the 75 th percentile and the 25 th $(\mathrm{p} 75 / \mathrm{p} 25)$.

- Four Generalized Entropy Indices $(\alpha=-1 ; 0 ; 1 ; 2) .{ }^{10}$

- Two Atkinson Indices $(\epsilon=0.5 ; 2) .{ }^{11}$

- The Gini coefficient.

Figure 2 shows the estimated Gini coefficient between 1957 and 2017. The blue dots are the Gini point estimates, whose volatility depends on the different sources used for the estimations of the income shares. We analyse the overall trend in inequality, represented by the red line which smooths the Gini point estimates through the application of the Hodrick-Prescott filter. From the graph, we can observe that inequality among European citizens is much lower nowadays than at the beginning of the European integration process.

We find an overall decrease in inequality using all the considered measures, which is clear both graphically in Figure 3 and quantitatively - through a regression of each

${ }^{10}$ The members of the Generalized Entropy class follow this general formula:

$$
I_{\alpha}(x)=\left(\frac{1}{\alpha(\alpha-1)}\right)\left[\left(\left(\frac{1}{N}\right) \sum_{i=1}^{N}\left(\frac{x_{i}}{\mu}\right)^{\alpha}\right)-1\right]
$$

where $\mathrm{N}$ is the total population, $x_{i}$ is the income of individual $i$ and $\mu$ is the mean income. The parameter $\alpha$ represents the weight given to distances between incomes at different parts of the distribution and it can take any real value. Low values of $\alpha$ give more importance to differences in the lower tail of the distribution, whereas high values stress the dispersion in the upper tail.

${ }^{11}$ The formula of the general Atkinson Index is:

$$
A_{\epsilon}(x)=1-\left[\left(\frac{1}{N}\right) \sum_{i=1}^{N}\left(\frac{x_{i}}{\mu}\right)^{1-\epsilon}\right]^{\frac{1}{1-\epsilon}}
$$

where $\mathrm{N}$ is the total population, $x_{i}$ is the income of individual $i$ and $\mu$ the mean income. $\epsilon$, taking values between 0 and $+\infty$, represents the degree of inequality risk-aversion; the higher it is, the more people are averse to inequality. 
inequality measure on time - in Table 2. The Gini coefficient diminishes on average by 0.002 each year, with a reduction of $30 \%$ per cent in 60 years; this is a relevant change. Moreover the other measures display an even higher decrease. Indeed, there are remarkable differences in the reduction among the measures, ranging from $29 \%$ for the interquartile ratio and $75 \%$ for the Generalized Entropy Index with $\alpha=2$.

According to all the different measures we compute, the decrease of inequality has not been linear in time. Inequality shows a higher decrease until the mid1980 s, then a stagnation and finally a rise from the beginning of the 2000s. Using a Chow test, we find statistical evidence of two structural breaks in the series of the Gini coefficient: a first one occurs in 1986 and a second one in 2000. The other measures of inequality display statistically significant structural breaks in the same two years or close. ${ }^{12}$ Therefore we divide the period of analysis into three subperiods, according to the years detected as a structural breaks for the Gini coefficient: 19571986, 1987-1999 and 2000-2017. ${ }^{13}$ In Table 3 we regress the inequality measures on time in each of the three subperiods: the time coefficient is generally negative and statistically significant before 1986, not statistically different from zero between 1987 and 2000 and positive and statistically significant after 2000. The average variation shows that the reduction in inequality is almost entirely concentrated in the first subperiod. It could be interesting to investigate the relationship between the reduction of inequality among citizens in Europe and the GDP growth rates since the drop in inequality seems to be higher in the 1960s and the 1970s, a period characterized by the rapid growth of the European countries. ${ }^{14}$

\subsection{Regional differences}

After analyzing the EU-15 as a unique country, we divide the 15 member states into four groups, characterized by different welfare state systems (see among others: Esping-Andersen, 1990; Gough et al., 1997; Arts and Gelissen, 2010):

1. Nordic countries: Denmark, Finland, Sweden.

2. English-Speaking countries: Ireland, United Kingdom.

3. Central Europe: Austria, Belgium, France, Germany, Luxembourg, Netherlands.

4. Southern Europe: Greece, Italy, Portugal, Spain.

The first three groups mostly reflect the classification of the Three Worlds by EspingAndersen (1990) (respectively the social democratic, the liberal and the conservative

\footnotetext{
${ }^{12}$ Only the percentile ratio p75/p25 presents structural breaks with a slightly different timing, since the first one occurs in 1979 and the second one in 2002.

${ }^{13}$ For better comparability, we consider the same subperiods for all the inequality measures: estimates would not change significantly by using for each measure the periods identified by the corresponding structural breaks.

${ }^{14}$ However, this link between distribution of income and GDP may be influenced by the methodology itself, that merges aggregate (GDP) and micro survey (income shares) data.
} 
model) and the fourth one allows for distinguishing the peculiarities of the Mediterranean countries (Ferrera, 2005).

The first panel of Figure 4 shows the evolution of the Gini coefficient in the Nordic Countries. The average reduction is 37\% (Table 4) and most of the decrease is registered before 1975 .

By contrast, in the UK and Ireland inequality increases by $41 \%$ (Table 4). The second panel of Figure 4, concerning these two countries, shows the rapid increase of the Gini coefficient during the 1980s. Since the United Kingdom has a population almost 6 times larger than Ireland, the trend depends on the evolution of inequality in the UK. The overall increase in inequality reflects the distributional effects of the policies run by Thatcher in the 1980s.

The first panel of Figure 5 illustrates the situation for Central Europe. The predicted value reduces by $44 \%$ in average (Table 4), more than in the Nordic countries. The 6 countries belonging to this group account for almost half of the population of the EU-15. Therefore they might be the engine of the reduction of inequality among citizens in Europe. It is worth noting that for Central Europe the Gini coefficient decreases quickly until the mid-1980s, then fluctuates and finally slightly increases after the mid-2000s.

At the beginning of the period of analysis the Gini coefficient in Southern Europe is lower than in Central Europe and in the Nordic countries (Figure 5). However it decreases at a slower rate than in those groups of countries, so that at the end inequality is higher. The overall decrease is only $26 \%$, as reported in Table 4.

The process towards a lower level of inequality is likely to be driven by the most populous member states. For this reason we consider France, Germany, Italy and the UK, since each one has more than $15 \%$ of the EU-15's population, and we compute the Gini coefficient excluding one of these countries at a time. As expected, according to column 8 in Table 4, the decrease would be very high without the UK; excluding France or Germany instead the reduction would be lower. So the process towards cohesion is led in particular by France and Germany. This is even clearer when studying the evolution of inequality for the founding member states (Belgium, France, Germany, Italy, Luxembourg, Netherlands): for them the Gini coefficient has fallen by $41 \%$ (Table 4, column 9), one third more with respect to the EU-15.

\section{Robustness checks}

\subsection{Shortcomings of the integration-of-kernels method}

The integration-of-kernels method has many shortcomings. First of all, assuming that GDP is distributed as income in household surveys creates distortions since, as Deaton (2005) notes, they measures different things. In addition, the inconsistencies in WIID due to the use of different sources are a serious problem. However, it is difficult to overcome these issues because of the unavailability of household surveys.

Moreover, there are many concerns with the use of kernel density estimation (KDE) with grouped data (Minoiu and Reddy, 2008). This statistical tool is particularly useful because it does not require prior beliefs about the data generating 
process and it reproduces the underlying density function from few data (Minoiu, 2007).

To make a brief review, KDE is a non-parametric way of estimating a probability density function. Let $X_{1}, \ldots, X_{N}$ be IID random variables from an unknown probability density function $f(x)$. The kernel density estimator is:

$$
\hat{f}_{h}(x)=\frac{1}{N h} \cdot \sum_{i=1}^{N} K\left(\frac{x-x_{i}}{h}\right)
$$

where $K$ is the kernel function and $h$ is the bandwidth, a parameter that specifies the half-width of the kernel, which is the density window around each point. Intuitively, each data point is the center of a normalized density function, the kernel, using the bandwidth as variance. All the estimated densities are summed up vertically, so where the points are denser the kernel density obtained by summation is higher.

A first concern with using KDE in this context is the application of nonparametric estimators. Yatchew (2007) argues that they can be used as a confirmation tool or in interpolating among close observations. Instead Sala-i-Martin (2006) uses KDE as a smoothing technique, starting from very few observations.

Second, KDE requires IID observations; clearly, this is not the case for grouped data like income shares in WIID. The observations in the underlying household surveys are IID. However, the observations from the surveys are arranged in ascending order and divided in equal-sized groups. For each group the mean income is calculated, so we have a linear function of order statistics. Then WIID reports the percentage of income owned by each group with respect to the overall income. The process of ordering the IID observations generates a complex correlation structure that biases the KDE even if averages of order statistics give richer information than small samples. Minoiu (2007) uses Monte Carlo simulations to determine the bias due to grouped data. Sala-i-Martin (2006) does not consider this an important theoretical issue.

KDE requires the choice of a kernel function and a bandwidth. The first is a weighting function and there are many possibilities in the literature (e.g., Epanechnikov, Gaussian, Parzen, Triangular, Uniform) but asymptotically all these kernels are almost equivalent. The estimates in Section 3 are based on the Gaussian kernel, as in Sala-i-Martin (2006). As a robustness check, we have implemented estimates using the Epanechnikov and the Parzen kernels and the results are almost identical.

By contrast, the choice of the bandwidth is generally crucial. Silverman (1986) proposes some rule-of-thumb bandwidths that are defined as optimal since they seek to minimize the mean squared error. In the previous sections we used the so-called "optimal bandwidth of Silverman", which is defined as:

$$
\text { Optimal of Silverman: } \hat{h}_{S}=0.9 * \min \left\{\frac{I Q R}{1.34}, \hat{\sigma}\right\} * N^{-\frac{1}{5}}
$$

where $I Q R$ is the interquartile range and $\hat{\sigma}$ the estimated standard deviation. As robustness checks, we apply other bandwidths, such as the "normal scale rule" $\left(\hat{h}_{N}=1.06 * \hat{\sigma} * N^{-\frac{1}{5}}\right)$, which has been proposed by Silverman (1986) too, and the 
oversmoothed bandwidth (Jann, 2007), which is the largest one consistent with a reasonable amount of smoothing, and is proportional to the normal scale rule bandwidth $\left(\hat{h}_{O} \approx 1.08 * \hat{h}_{N}\right)$. These 3 bandwidths assume a normal distribution for the data. By contrast, the Sheather-Jones plug-in estimator is completely data driven and it has been shown to outperform other bandwidths; in this study we consider a variant of it, the direct plug-in estimator (Wand and Jones, 1995). Sala-i-Martin (2006) uses a hybrid bandwidth, equal to the optimal of Silverman but replacing $\min \left\{\frac{I Q R}{1.34}, \hat{\sigma}\right\}$ with $\hat{\sigma}$. In addition, he keeps this bandwidth constant between countries and years, saying that this allows for a better understanding of the dispersion trend. Actually, this bandwidth does not possess theoretical underpinnings since it is not optimal in any sense.

In the first five rows of Table 5 we observe the average percentage variations of the inequality measures obtained by using different bandwidths with the integrationof-kernels method. ${ }^{15}$ The inequality measures we consider display a very similar reduction in percentage terms using any bandwidth. The only exception is the constant bandwidth proposed by Sala-i-Martin that leads to a lower decrease but, as we mentioned above, is not an optimal choice.

Table 6 reports the percentage variations in the three subperiods defined in Section 3: 1957-1986, 1987-1999 and 2000-2017. For each period, the first rows show the percentages obtained using different bandwidths. We confirm that the reduction in inequality is concentrated in the first subperiod, regardless of the bandwidth that is applied. The constant bandwidth produces a lower decrease than other bandwidths, but it still confirms that inequality mostly dropped before 1986 .

Finally, we compare the Gini coefficient obtained through the integration-ofkernels method with the one computed through household surveys. The comparison can be done at the country level after 1995 using data from Eurostat. As it is shown in Figure 6, the integration-of-kernels method delivers higher levels of the Gini coefficient. However, the overall trend is consistent with the one based on income surveys, providing an indirect confirmation of the main results in Section 3.

\subsection{Other methodologies and further checks}

In the previous subsection we have explained some shortcomings of the integrationof-kernels method. Here, we apply four alternative methodologies and we show that the results are still consistent.

First of all we present a parametric version of the integration-of-kernels method, as in Pinkovskiy and Sala-i-Martin (2009). The distribution of log income can generally be approximated by a normal. ${ }^{16}$ Therefore, assuming that this is true also for grouped data, we estimate for each country and for each year a lognormal density function with mean and variance of the decile data. As in the KDE case, we rescale the density functions for their own populations and finally we sum up the

\footnotetext{
${ }^{15}$ The percentages shown in Table 5 are calculated like those in Table 2 by using the coefficients estimated through a linear regression of the inequality indicator on time. The estimated coefficients, which are not displayed in the table, are always statistically significant.

${ }^{16}$ The normal distribution is less precise for the top tail of the income distribution.
} 
national distributions in order to find the European one. We call this the second methodology.

With the integration-of-kernels method each single national density is estimated with only ten observations. Of course the estimated distribution of income is not very accurate. Moreover, all the errors committed in the KDE of each country are summed up in the European income distribution. For this reason we apply a KDE directly to all the observations of the EU-15 countries in a given year. After rescaling for the population of Europe, we can integrate the function between two near log points to find the number of citizens with a particular level of income. This is called the third methodology and it has also a parametric version, which consists in estimating a normal distribution with mean and variance of the observations in a given year, weighted with the number of people in the decile.

Finally, the fourth methodology is proposed by Sala-i-Martin (2002). It does not use KDE, overcoming the concerns presented by Minoiu and Reddy (2008), but it assumes that all the individuals in the same decile have equal income. All the inequality measures are computed weighing each observation with the number of people in the decile.

Table 5 collects the percentage changes of the inequality measures for the EU15 using all the different methodologies. The income convergence process among European citizens that we have described above is always confirmed. The reductions are quantitatively similar whatever the applied methodology. ${ }^{17}$

Finally, Figure 7 shows the years in which structural breaks occur. In the first panel all methodologies and inequality measures are considered jointly: the first structural break generally occurs between 1983 and 1986, the second in 2000-2001. The second panel shows how the structural breaks occur for each inequality measure: the p75/p25 presents the largest variability among the considered indicators. In Table 6 we compare the results in the three subperiods 1957-1986, 1987-1999 and 2000-2017: we confirm our result that inequality reduced mostly before 1986 and started increasing again in the 2000s.

\section{Conclusions}

In this study we estimate the evolution of the European income distribution from 1957 to 2017. The focus is not on regional convergence, which has been discussed extensively in the literature, but on the change in inequality among European citizens.

Since national survey data on income are not directly available for the entire period, we apply the integration-of-kernels method proposed by Sala-i-Martin (2006). The data we use mostly come from the Penn World Table (population and real GDP per capita in PPP) and WIID (income shares).

We discover that social cohesion in the EU-15 has increased. The income distributions of the most populous member states have converged (Figure 1) and the Gini

\footnotetext{
${ }^{17}$ The percentage variations are slightly smaller applying the constant bandwidth, both in the third methodology and in the integration-of-kernels method.
} 
coefficient has diminished (Figure 2) by nearly 30\%. All the inequality measures we use show a remarkable reduction. The decrease was very rapid until the mid-1980s. It then slowed gradually, to the point that inequality started rising at the beginning of the 2000s.

We divide the EU-15 member states into four macro areas: Nordic countries, Central Europe, Southern Europe and English-Speaking countries. We find an increase in income dispersion only in the last group. The decrease in inequality in the whole EU-15 is guided by Central Europe with a major role played by France and Germany. This is clear also looking at the EU-6, the group of six countries that signed the Treaty of Rome in 1957. Among them the Gini coefficient has decreased by $41 \%$.

The integration-of-kernels method is a rough approximation and the use of secondary data as WIID leads to possible pitfalls. Moreover, applying KDE to grouped data is controversial. However, it is not possible to overcome all these problems because of the unavailability of household surveys for each year and each country. Therefore in order to check the robustness of our results we apply four other methodologies. The findings are consistent with the integration-of-kernels method.

The reduction in inequality found in our study cannot be adduced as evidence for or against the benefits of the integration process. However, having reliable estimates of the overall trend is extremely useful because it is a starting point for further investigations. In particular, since the decrease in the Gini coefficient has been higher for the founding countries of the European Economic Community, it would be interesting to analyze the relationship between the integration process and inequality among citizens. The convergence process was very rapid up to the mid-1980s, when cohesion policies did not play such a key role in the European budget as in the following decades. These policies are more focused on regional convergence but it is important to also assess their impact on income distribution among European citizens. 


\section{A Tables and Figures}

Table 1: Income shares from WIID used in the estimations

Country Obs. First obs. \% of 2017 EU's pop.

\begin{tabular}{|c|c|c|c|}
\hline Austria & 24 & 1983 & 2.1 \\
\hline Belgium & 26 & 1969 & 2.8 \\
\hline Denmark & 38 & 1952 & 1.4 \\
\hline Finland & 39 & 1952 & 1.4 \\
\hline France & 29 & 1956 & 16.5 \\
\hline Germany & 22 & 1989 & 20.2 \\
\hline GermanyEast* & 3 & 1967 & 4.6 \\
\hline GermanyWest* & 15 & 1950 & 16.9 \\
\hline Greece** $^{* *}$ & 23 & 1958 & 2.7 \\
\hline Ireland & 26 & 1973 & 1.2 \\
\hline Italy $* * *$ & 43 & 1948 & 14.6 \\
\hline Luxembourg & 25 & 1985 & .1 \\
\hline Netherlands & 28 & 1950 & 4.2 \\
\hline Portugal & 23 & 1980 & 2.5 \\
\hline Spain & 27 & 1965 & 11.4 \\
\hline Sweden & 34 & 1948 & 2.4 \\
\hline United Kingdom & 56 & 1961 & 16.3 \\
\hline
\end{tabular}


Figure 1: Income distribution (Integration-of-kernels method)

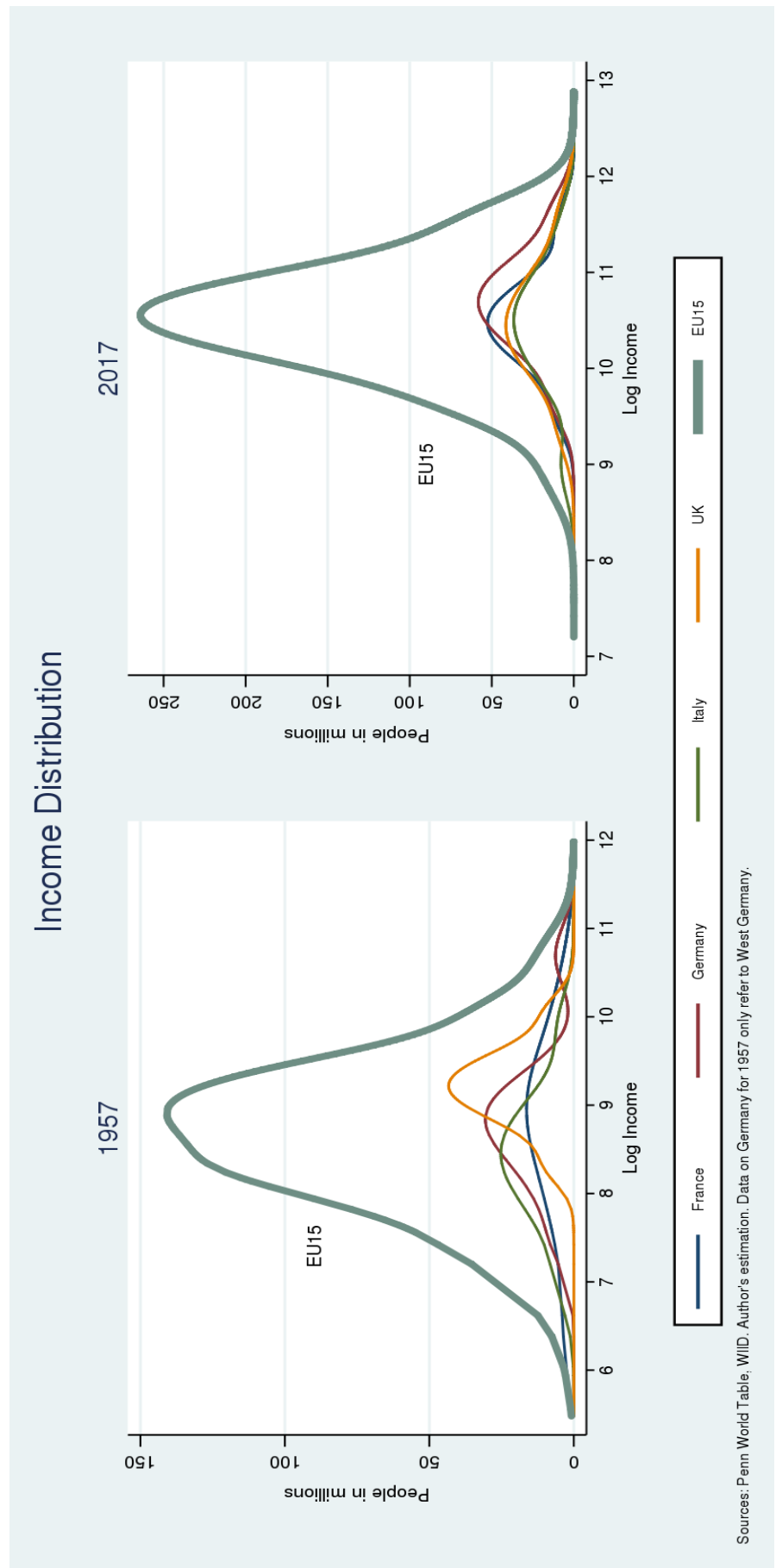


Figure 2: Gini coefficient in EU-15 (Integration-of-kernels method) (1957-2017)

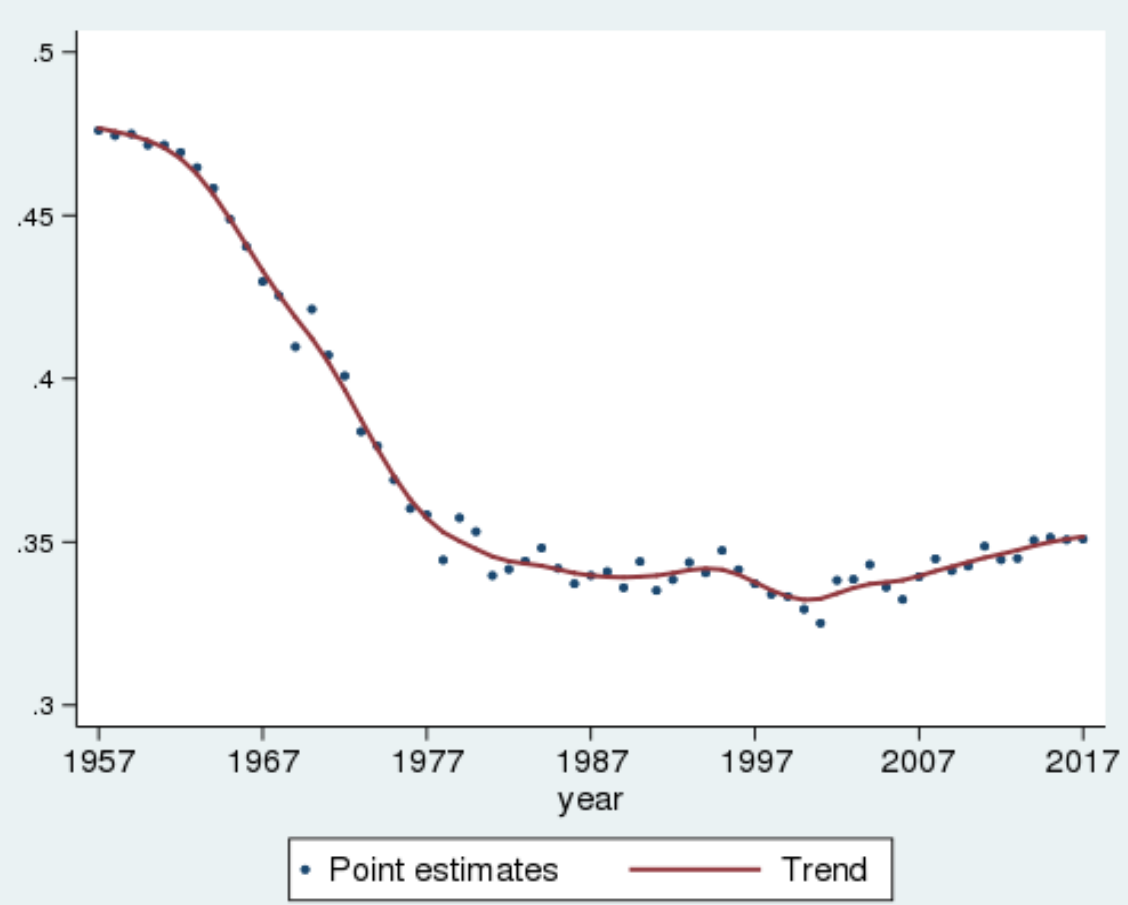

Sources: Pern World Table, WIID. Author's estimation. 
Figure 3: Inequality measures in EU-15 (Integration-of-kernels method) (1957-2017)
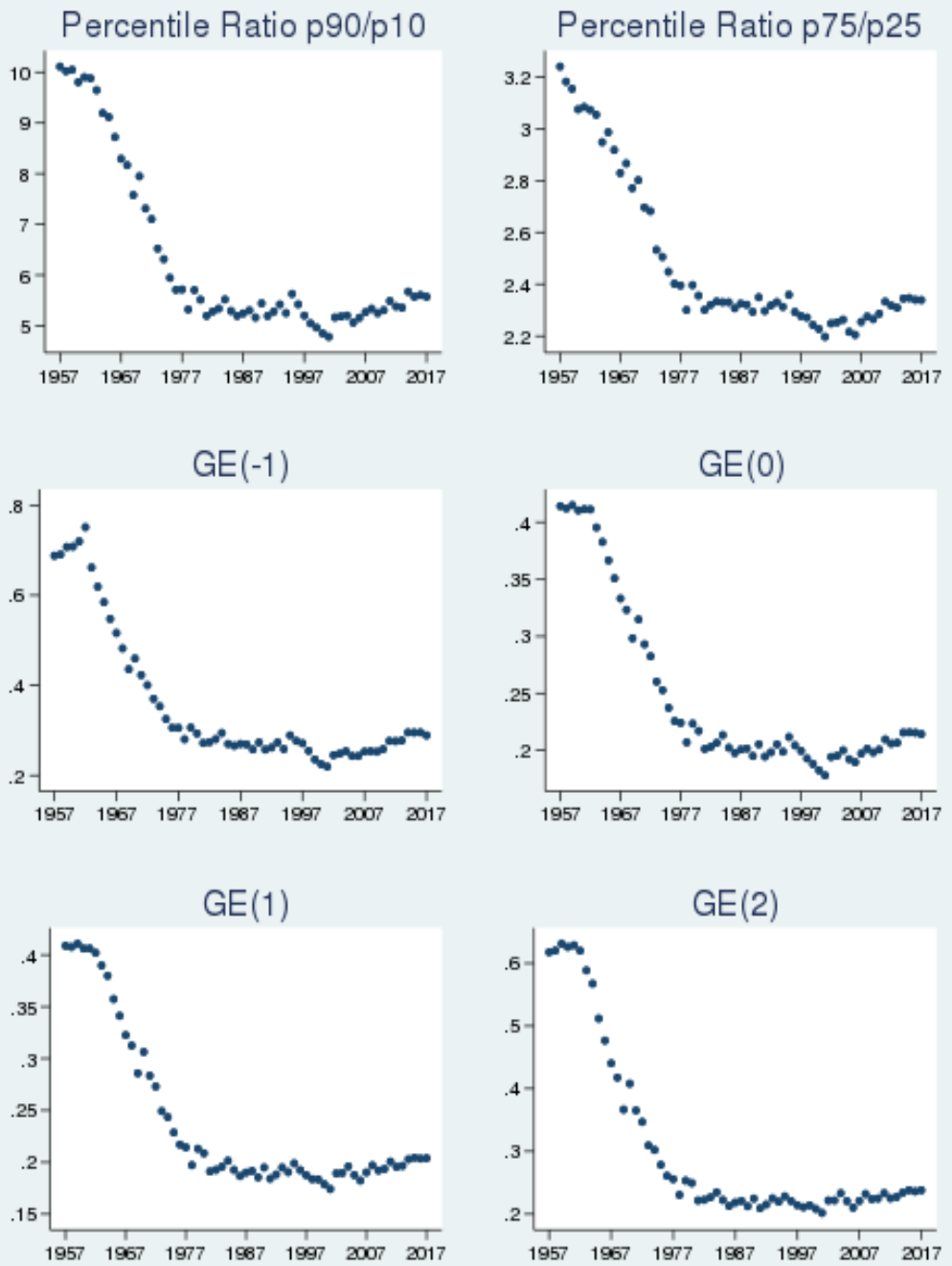

Atkinson Index(0.5)

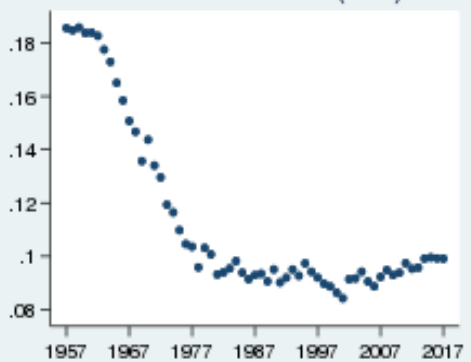

Atkinson Index(2)

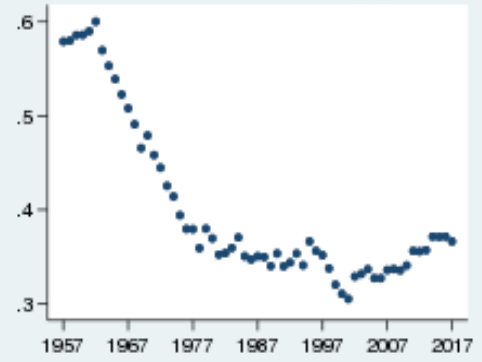

Sources: Penn World Table. WIID. Author's estimation 


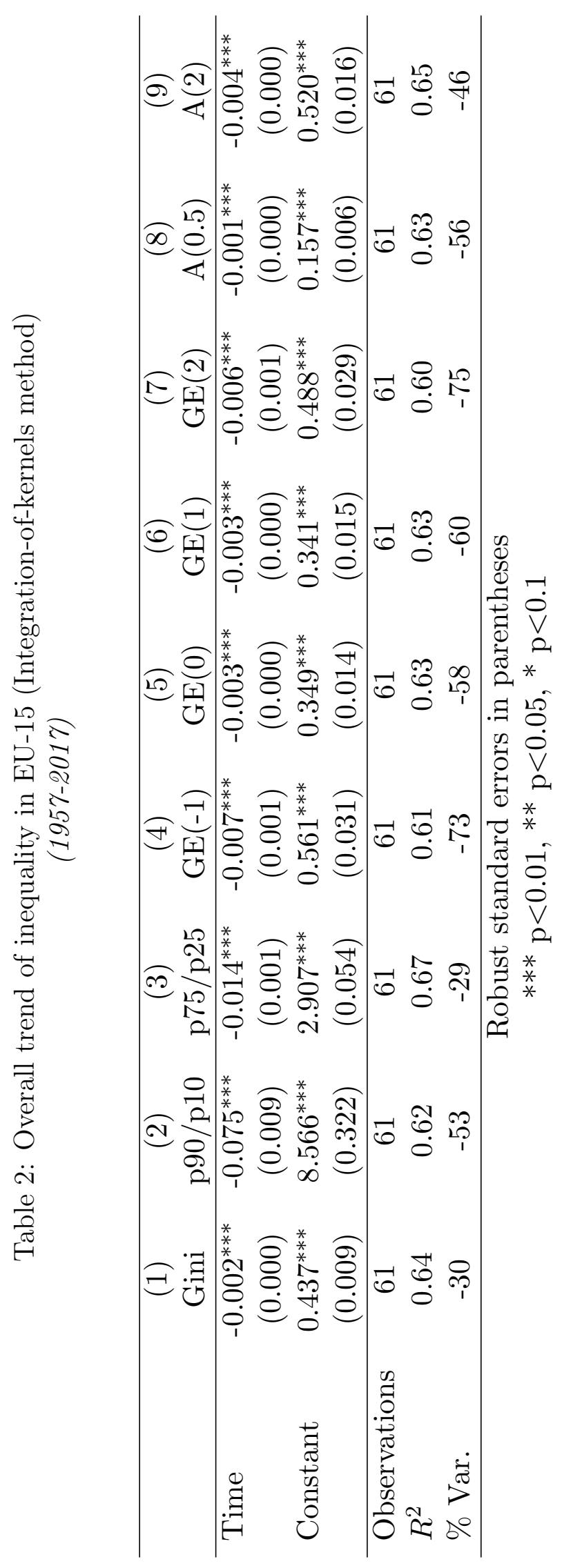




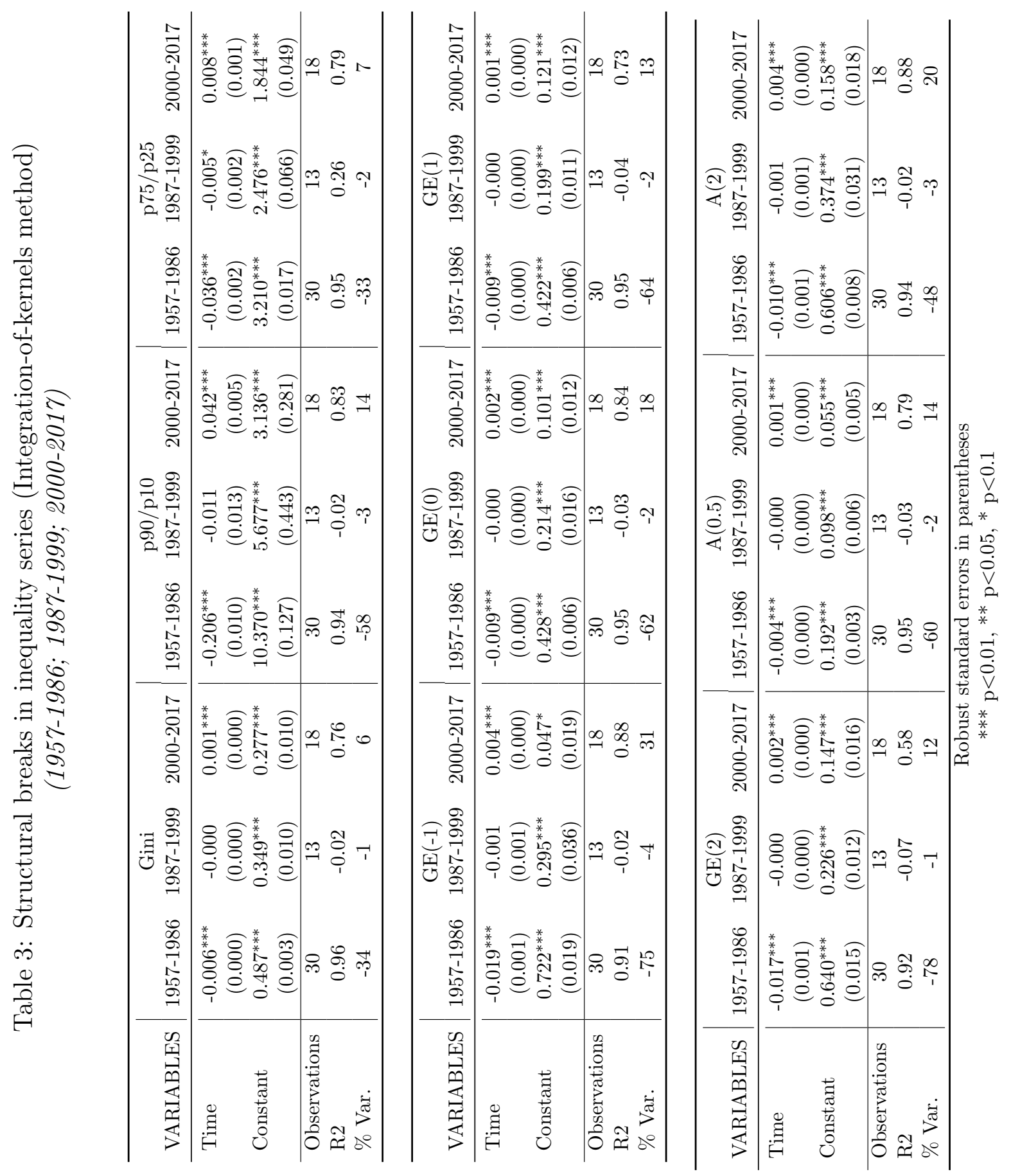


Figure 4: Gini coefficient in Nordic and English-Speaking countries (Integration-of-kernels method)

(1957-2017)

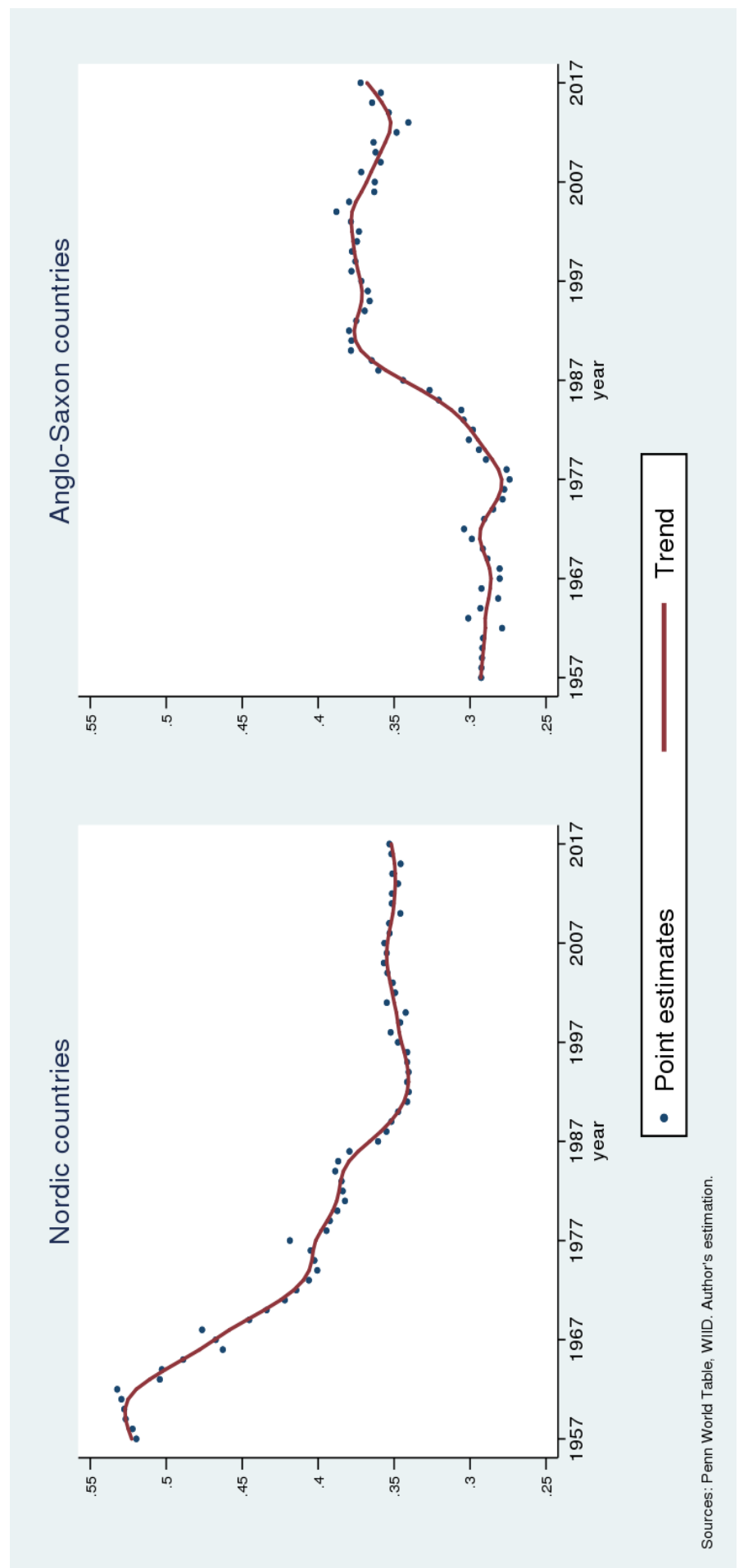


Figure 5: Gini coefficient in Central and Southern Europe (Integration-of-kernels method)

(1957-2017)

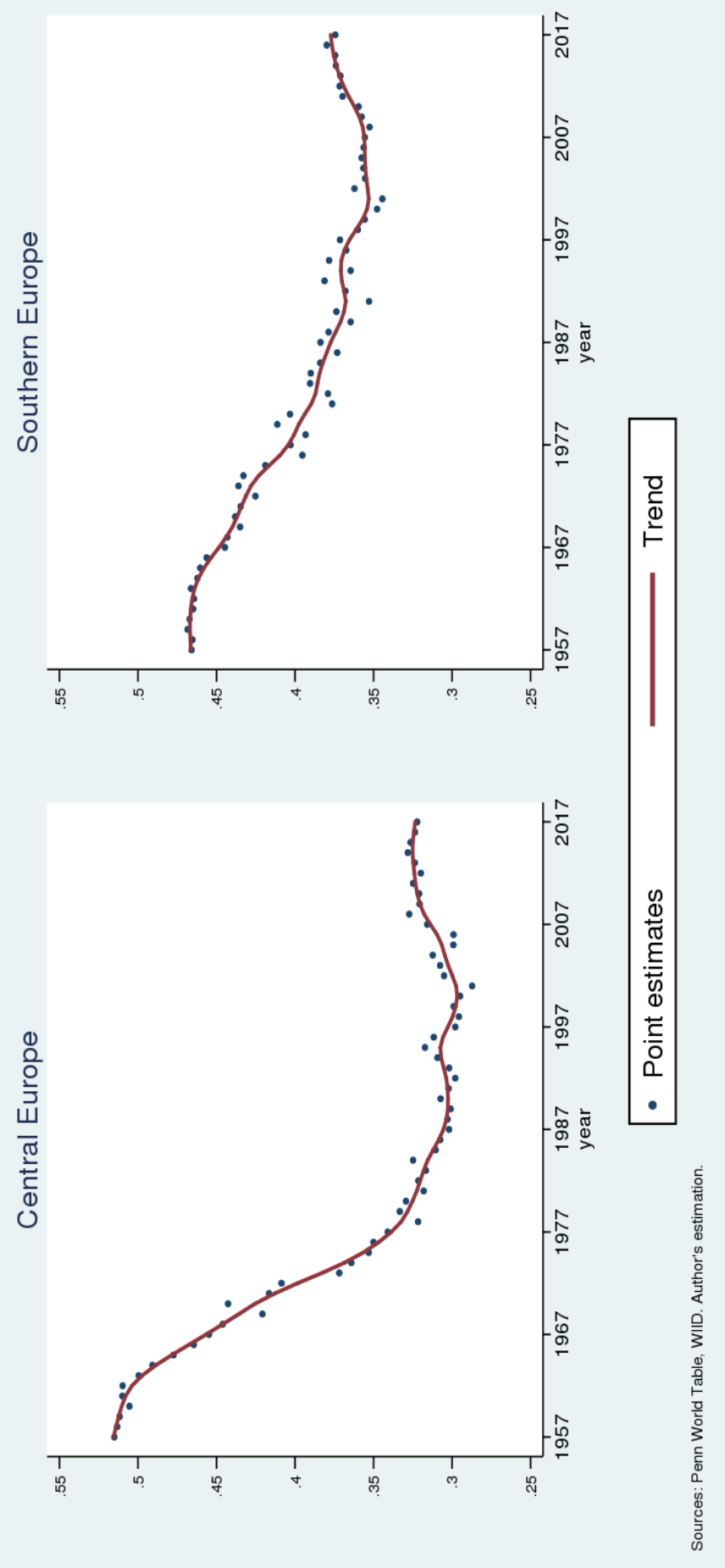




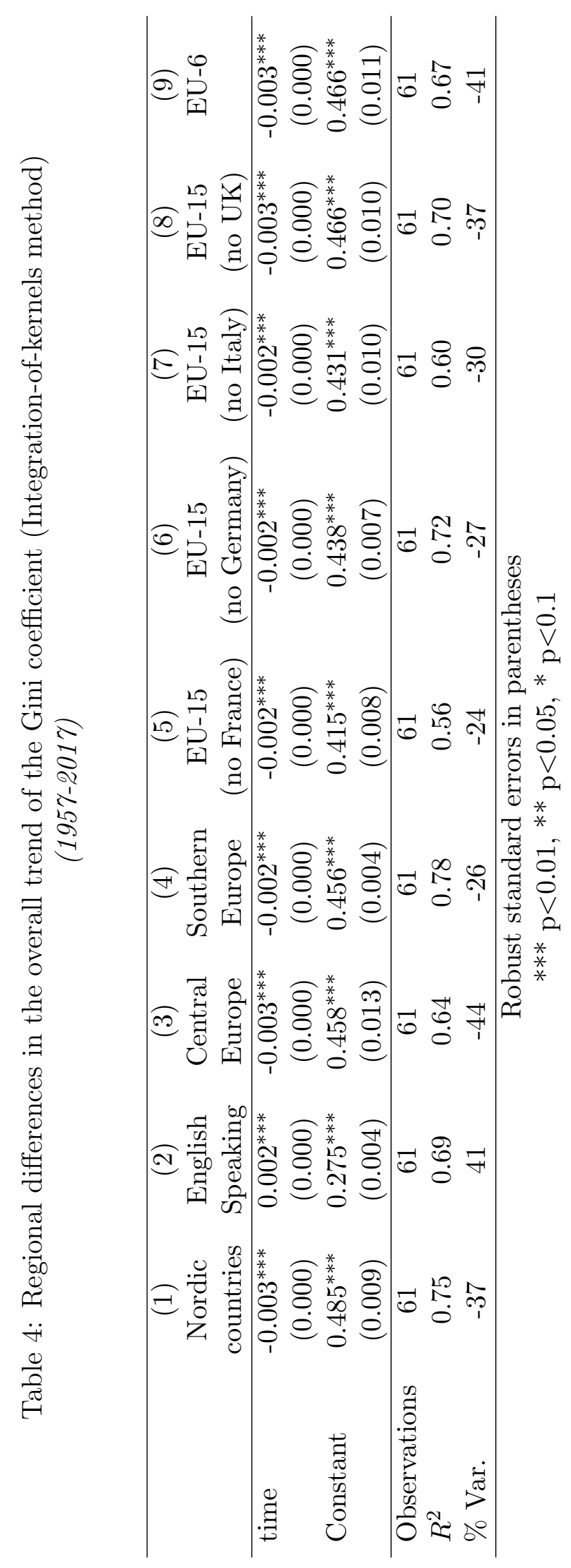




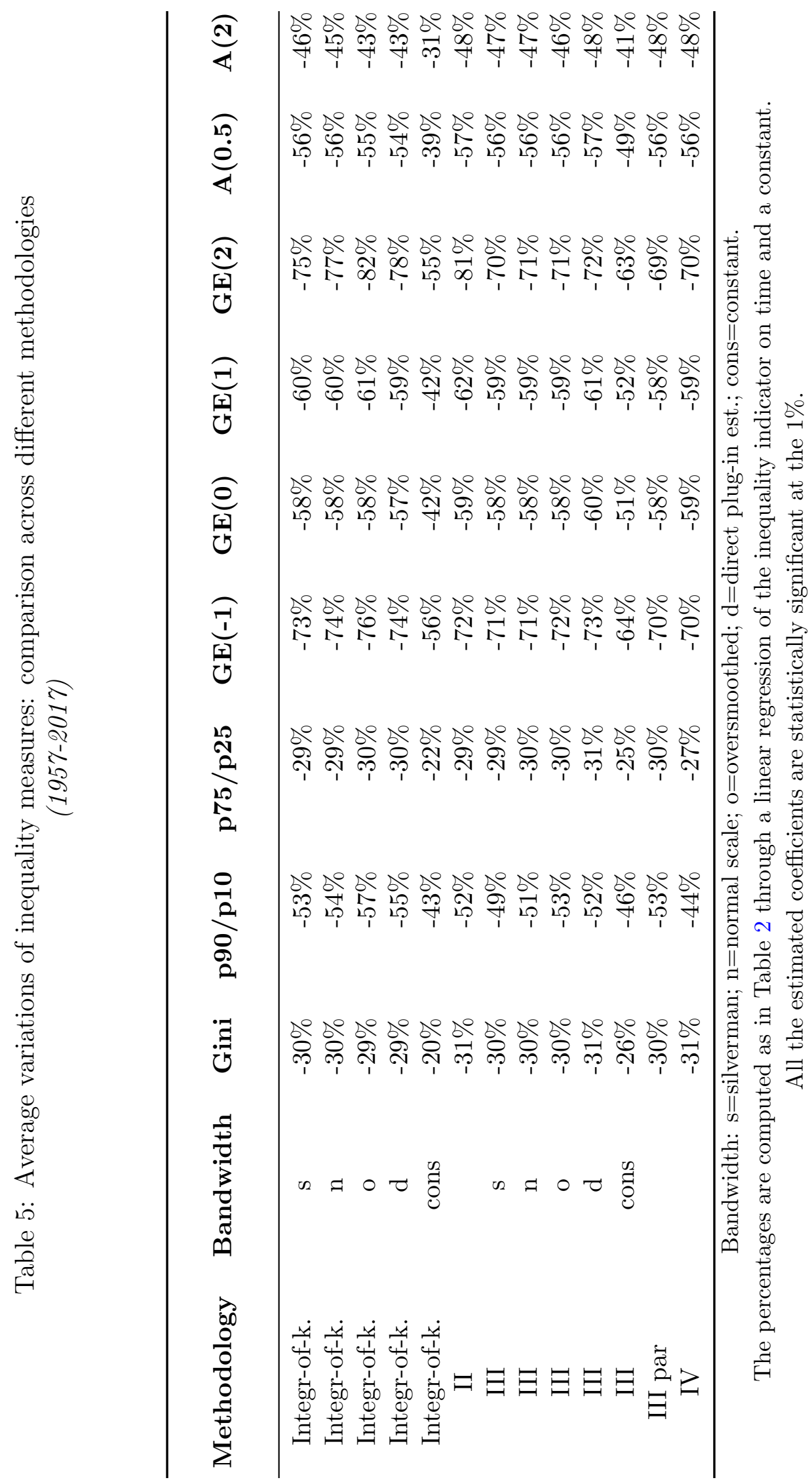




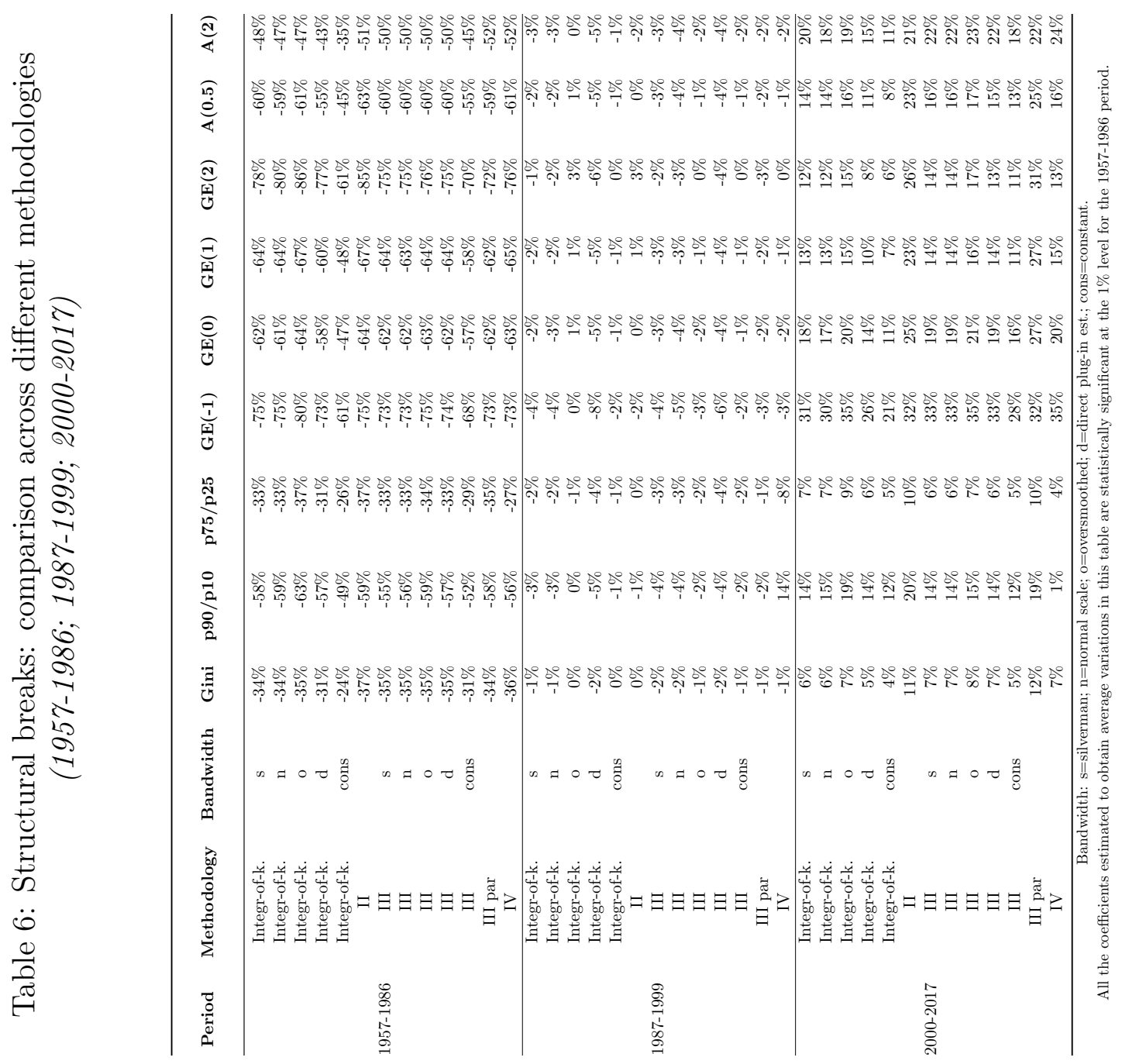


Figure 6: Gini coefficient: Comparison between integration-of-kernels method and survey data

(1995-2017)

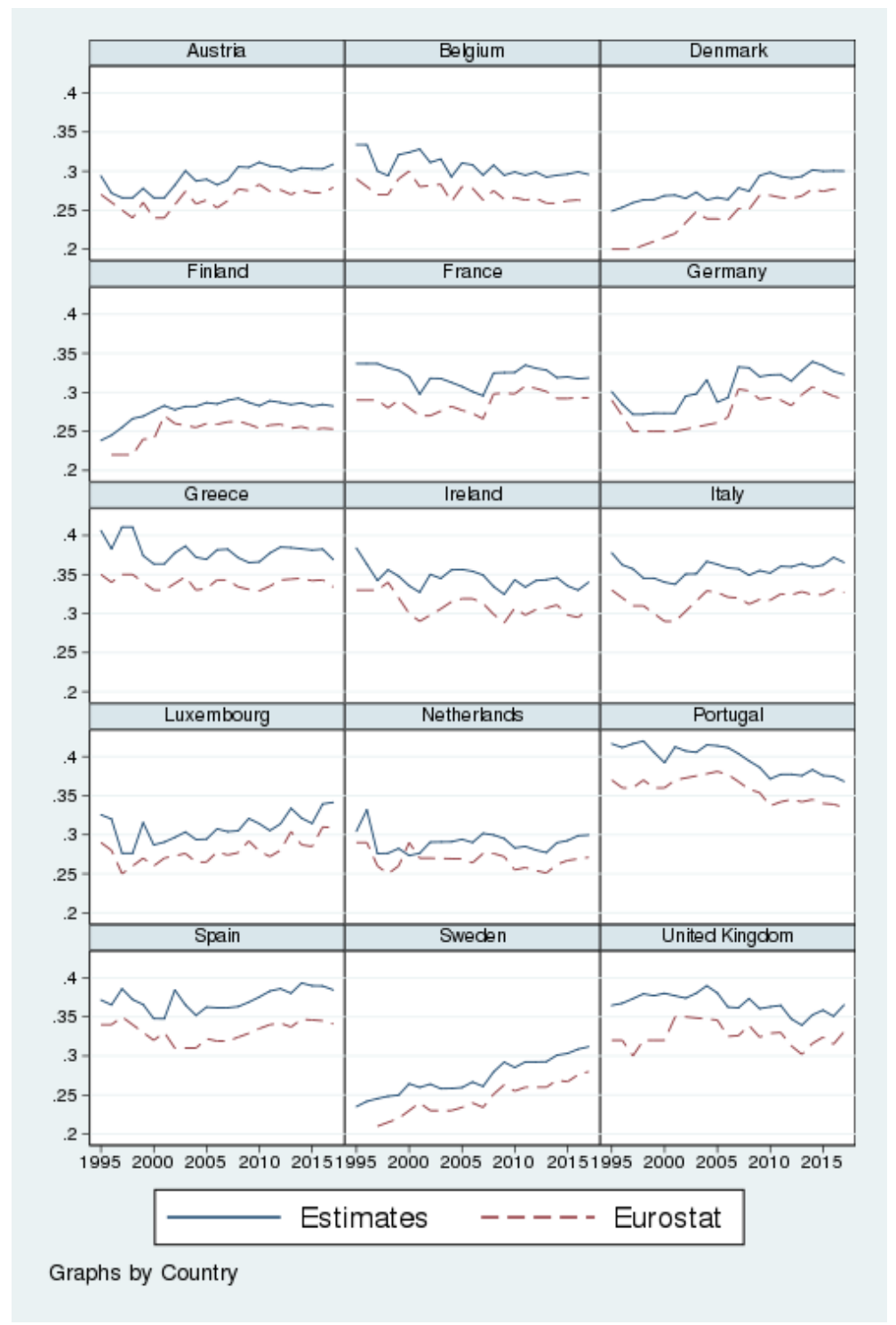


Figure 7: Structural breaks (Integration-of-kernels method) Europe of 15

(1957-2017)

\section{All methodologies}

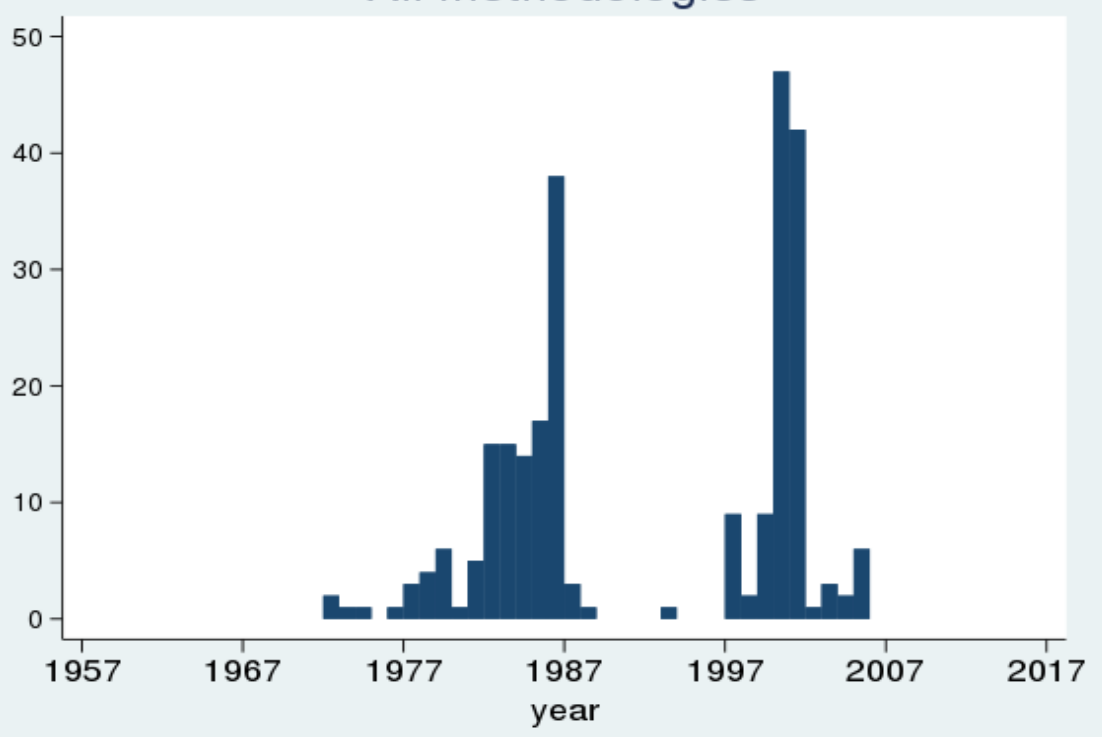

By inequality measure

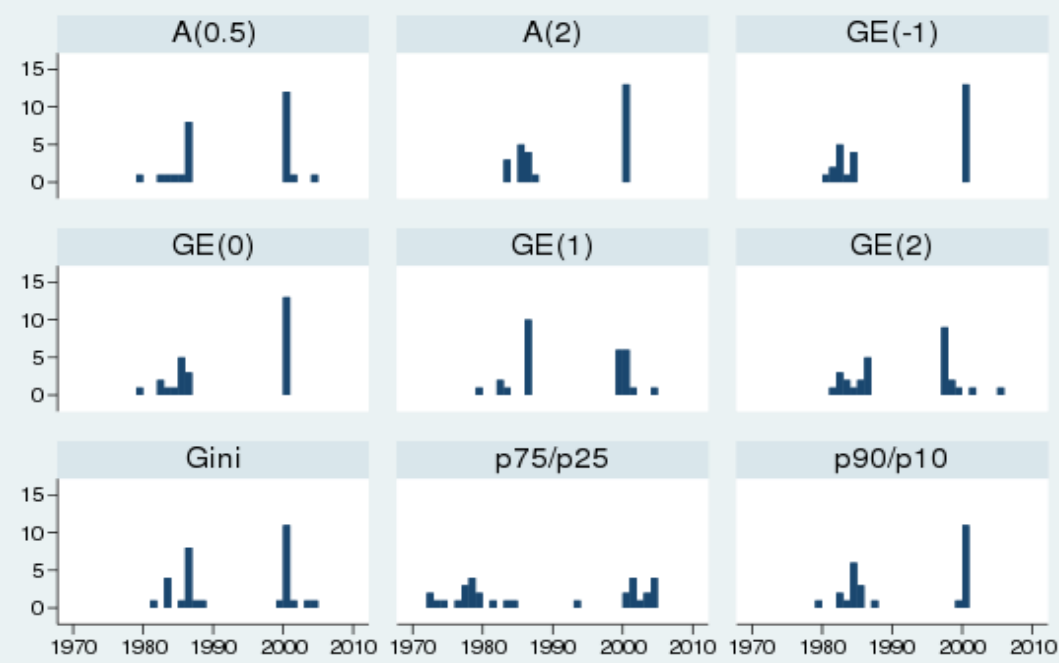

Graphs by inequality measure

Author's estimation. 


\section{B Decile estimates}

Figure 8: Available data on income shares and estimated values First decile

\section{Decile: 1}

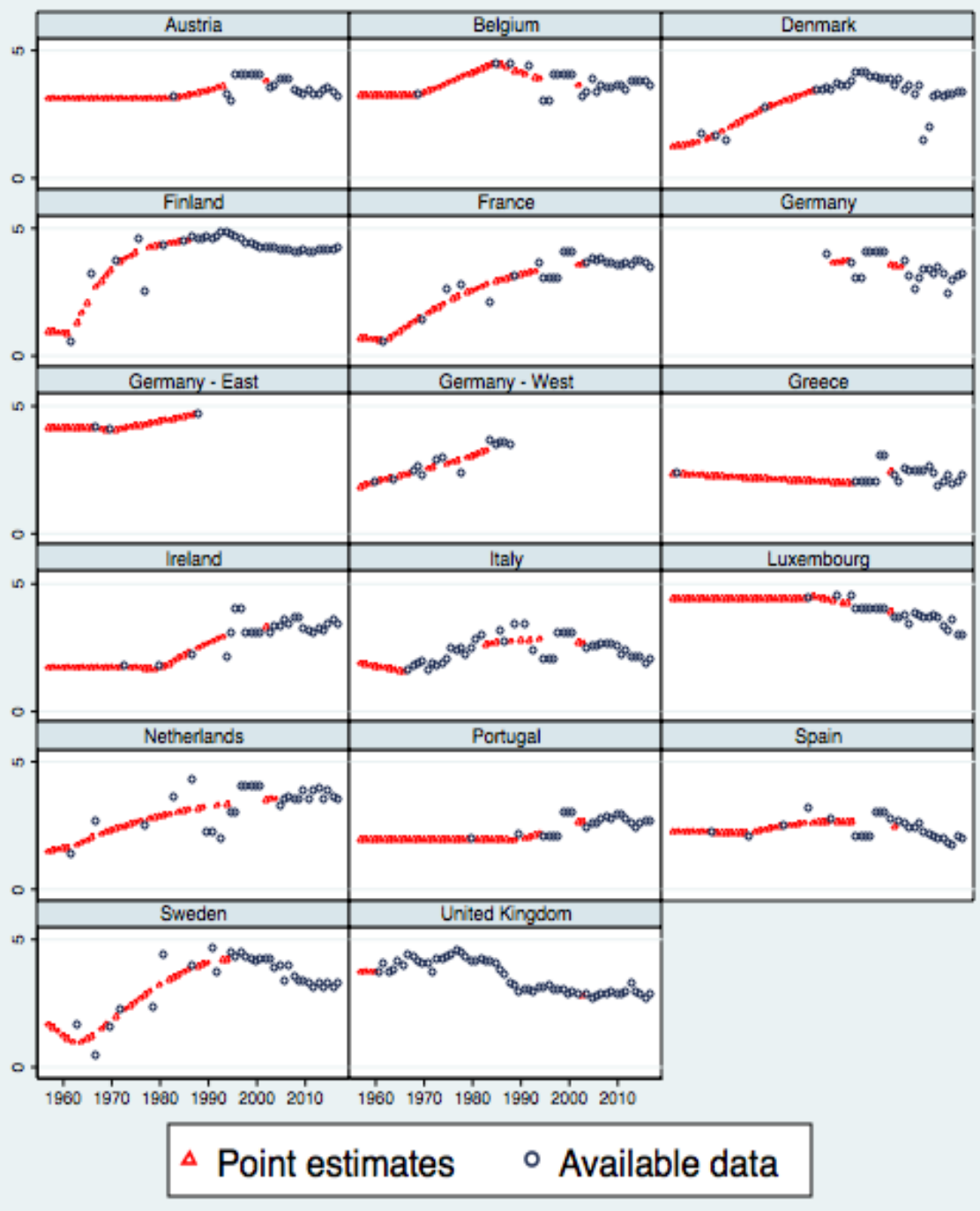

Graphs by Country 
Figure 9: Available data on income shares and estimated values Second decile

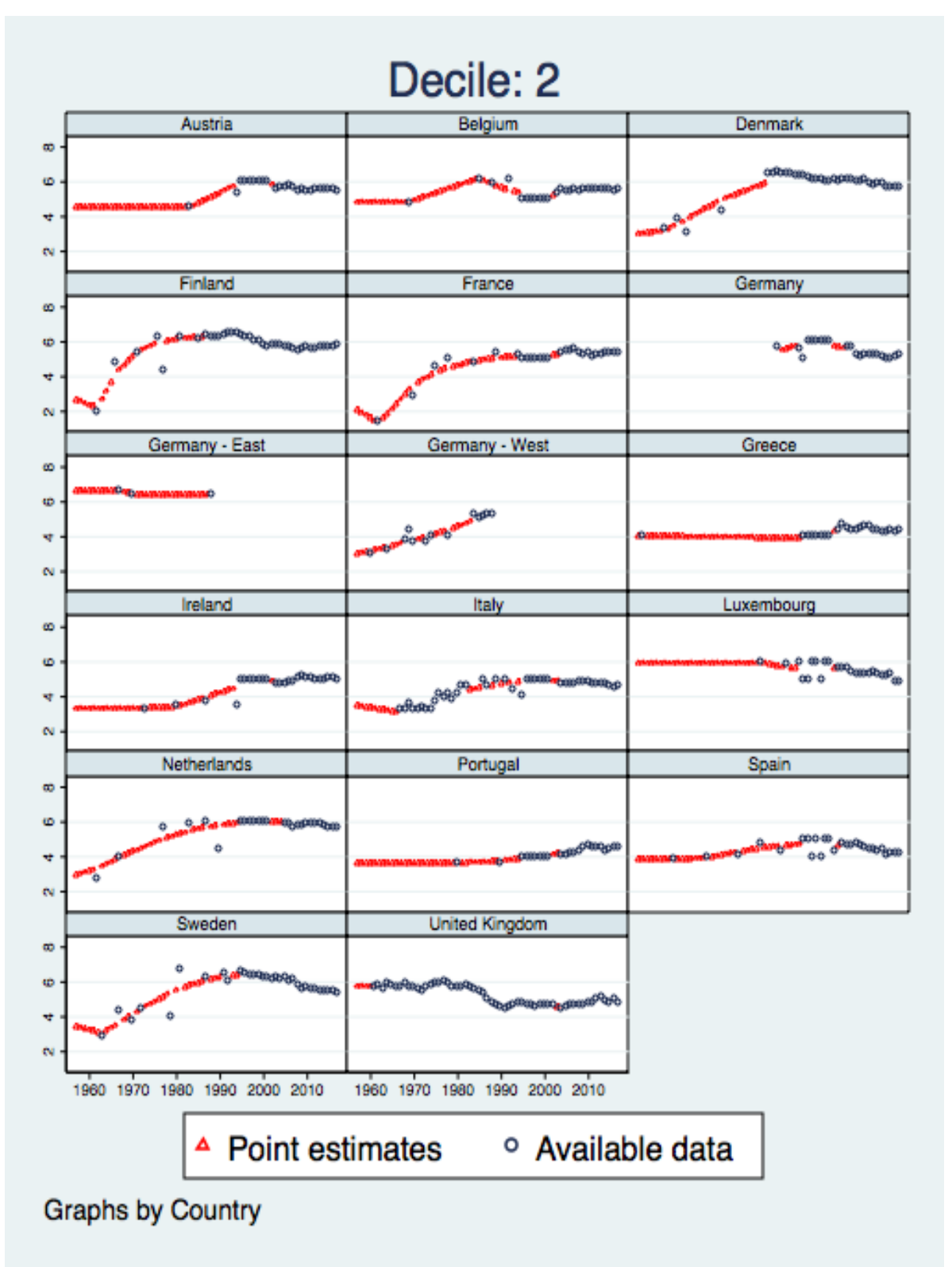


Figure 10: Available data on income shares and estimated values Third decile

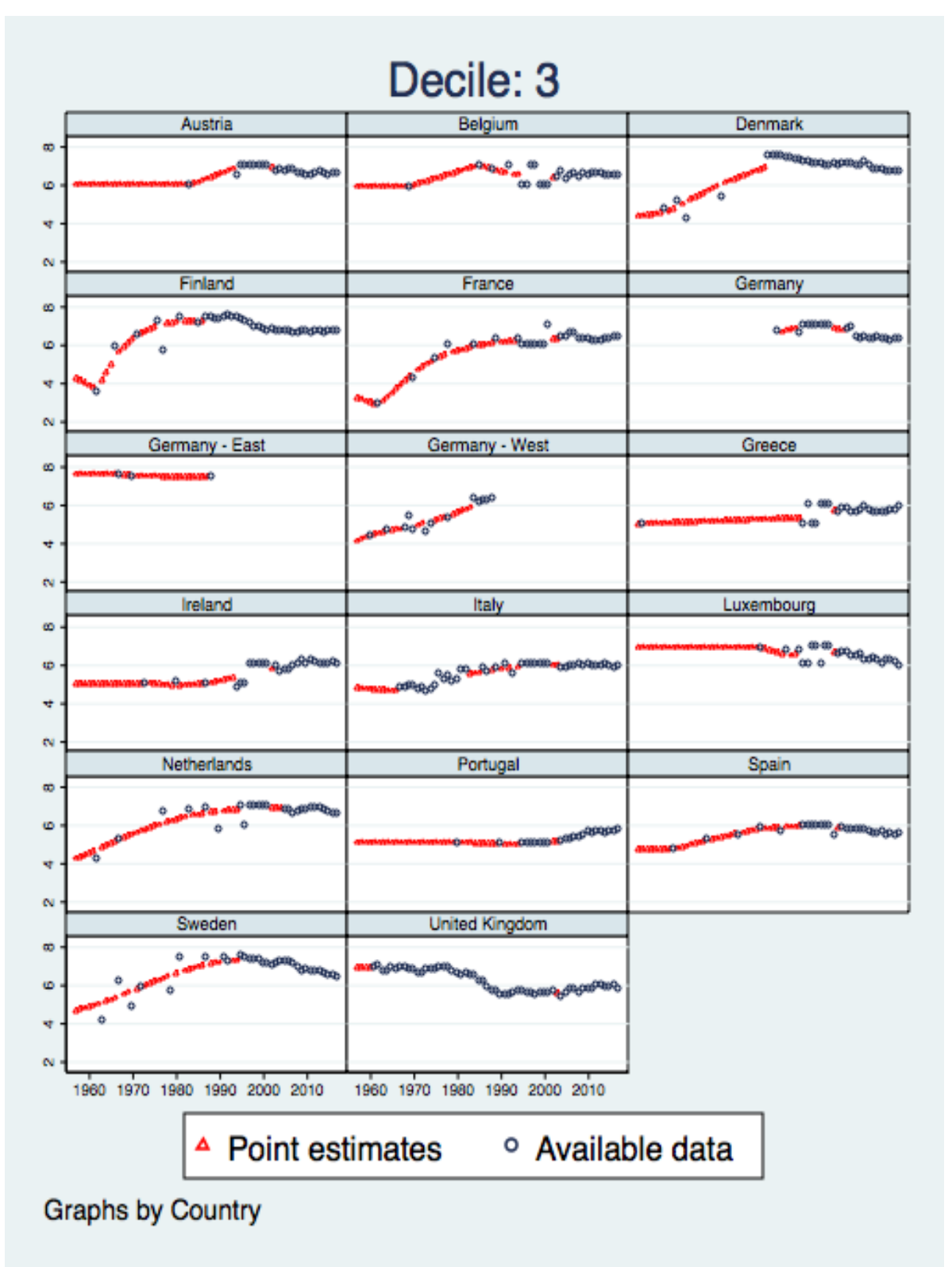


Figure 11: Available data on income shares and estimated values Fourth decile

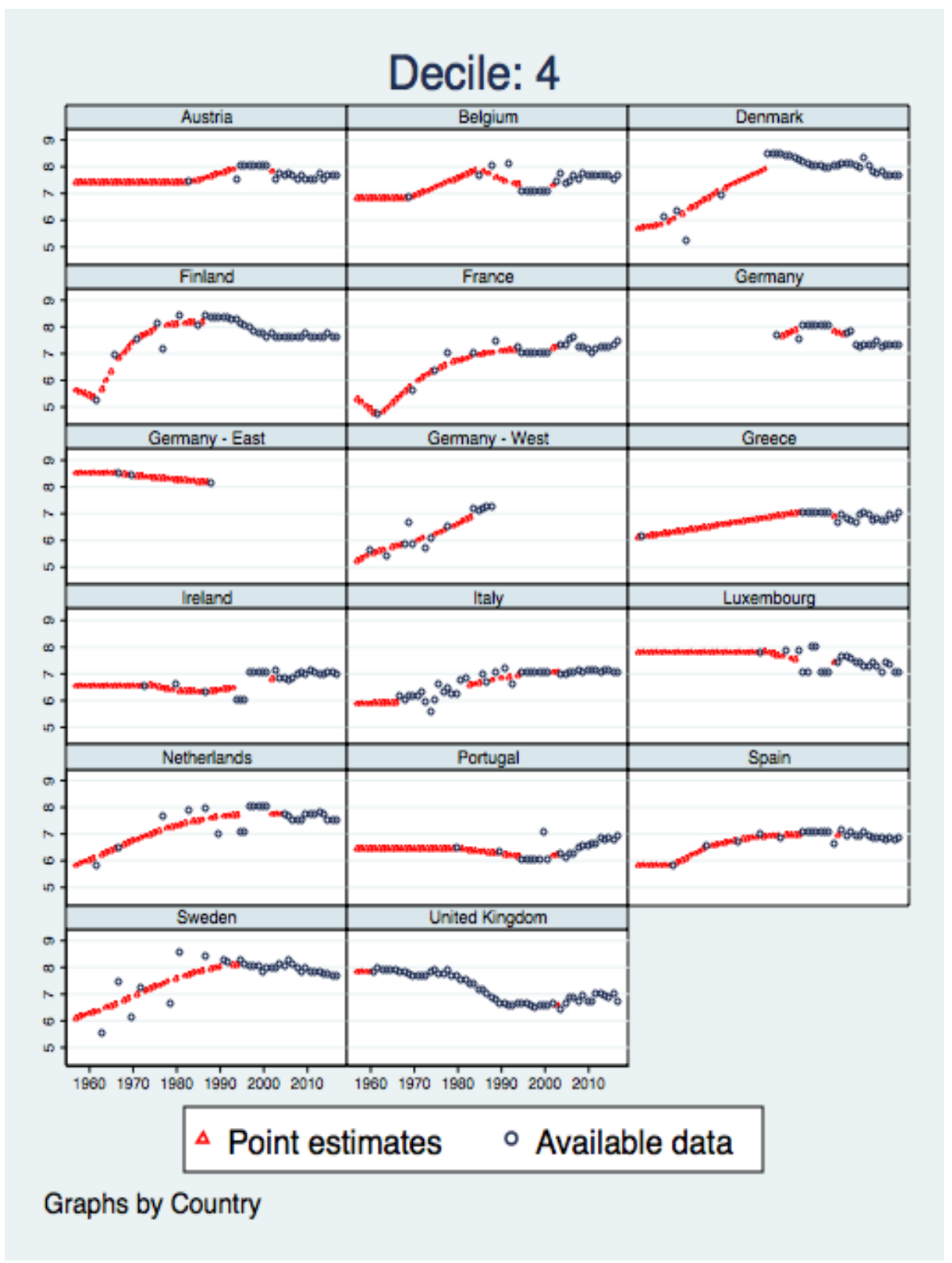


Figure 12: Available data on income shares and estimated values Fifth decile

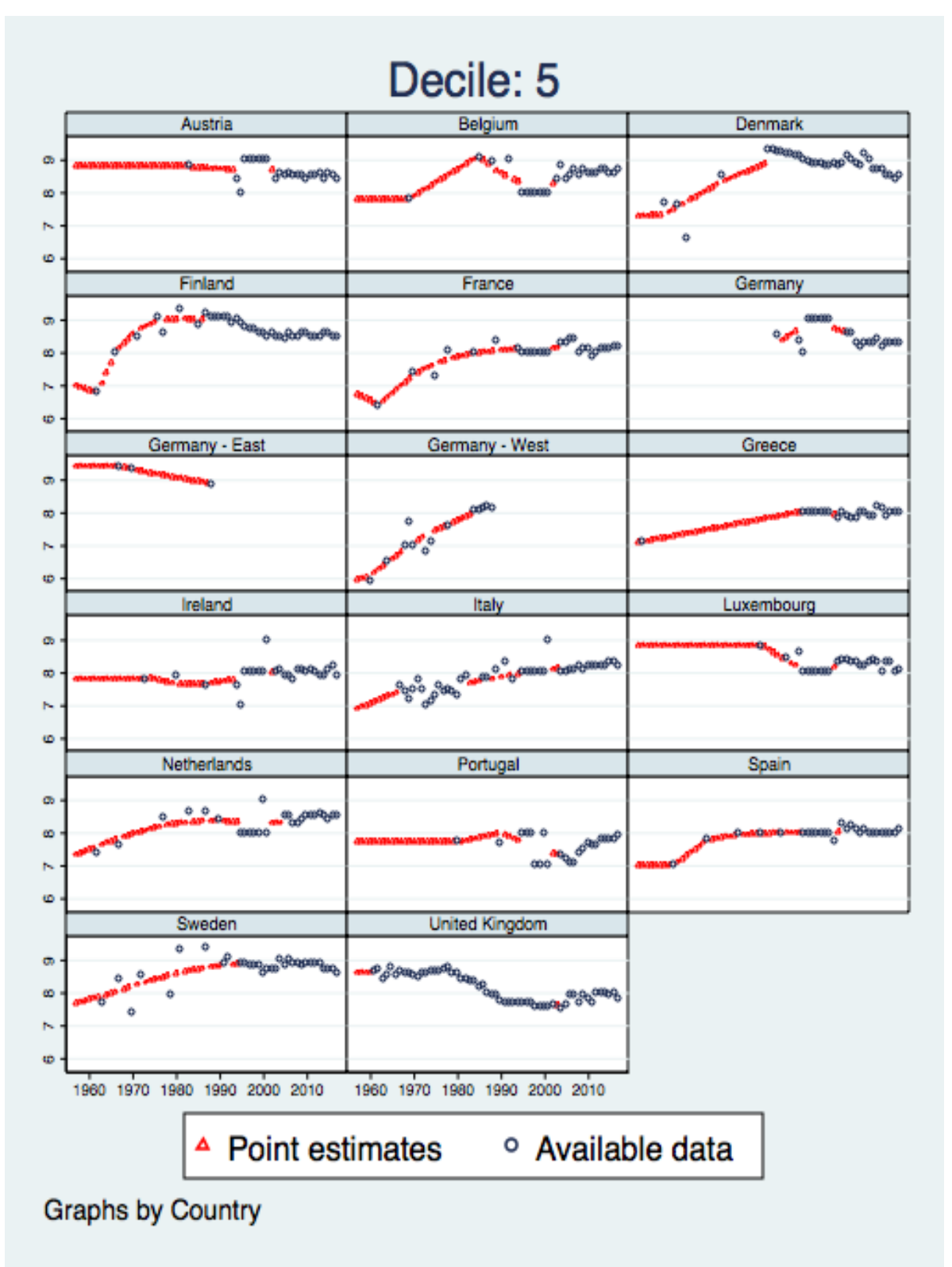


Figure 13: Available data on income shares and estimated values Sixth decile

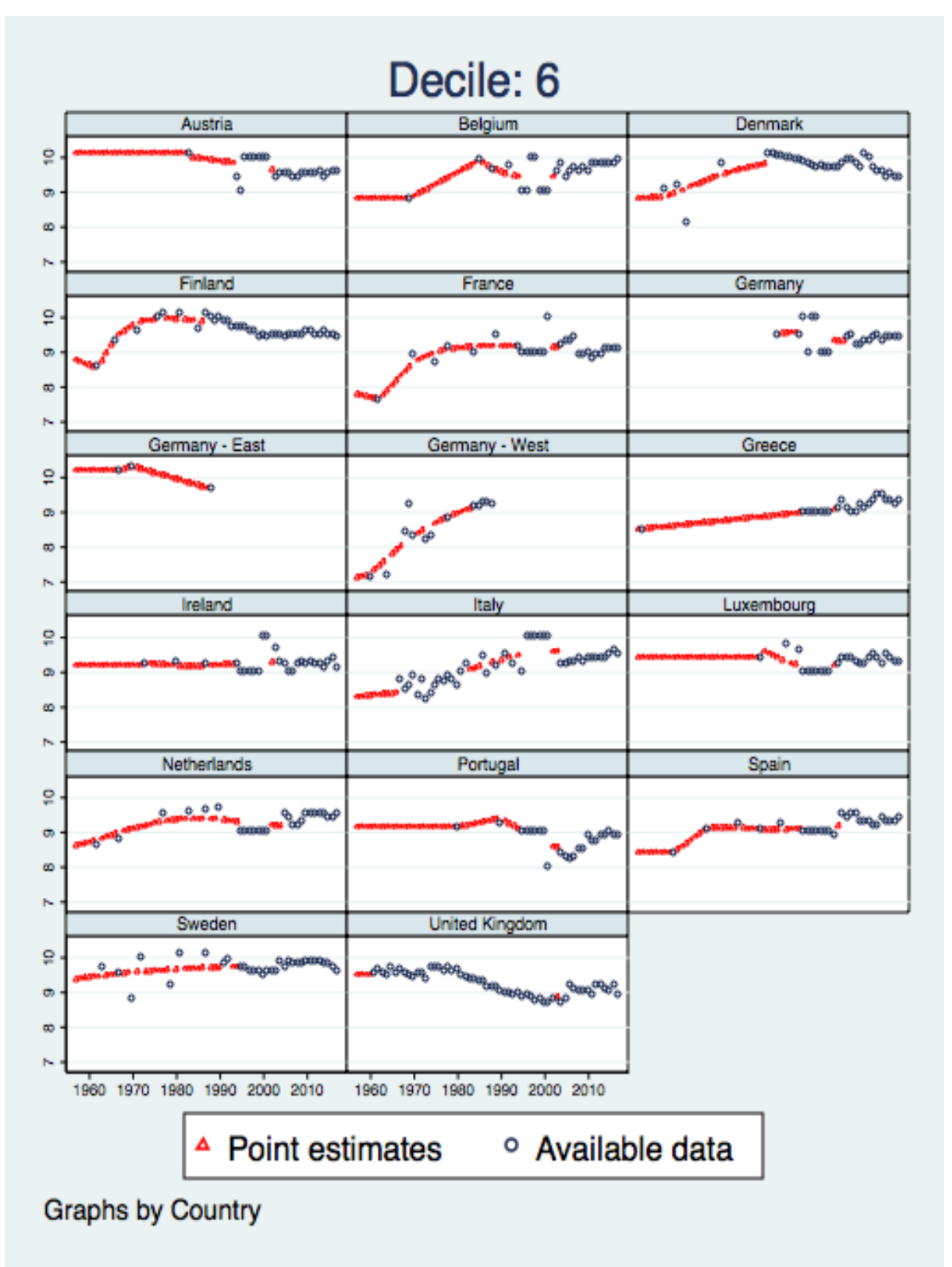


Figure 14: Available data on income shares and estimated values Seventh decile

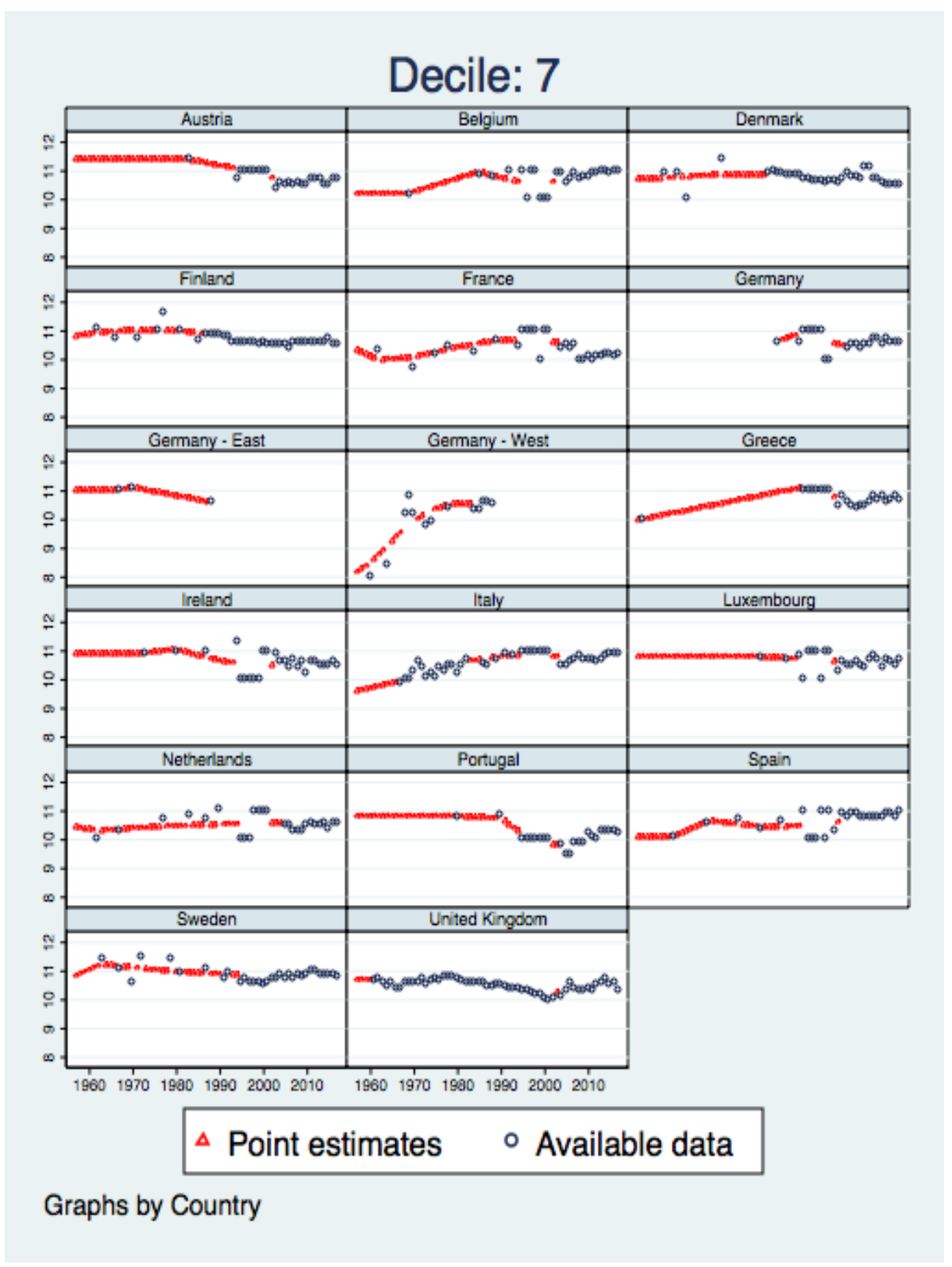


Figure 15: Available data on income shares and estimated values Eighth decile

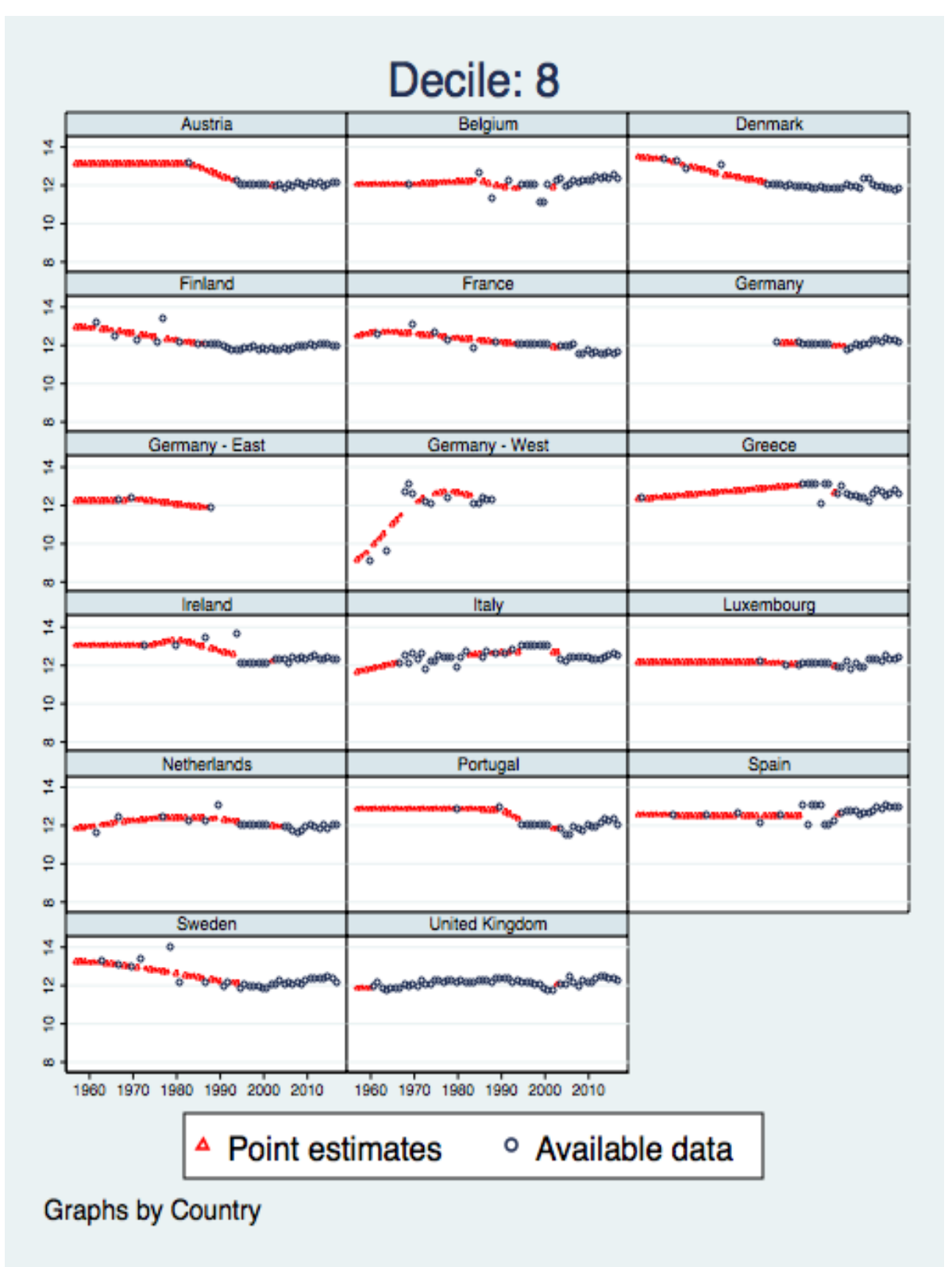


Figure 16: Available data on income shares and estimated values Ninth decile

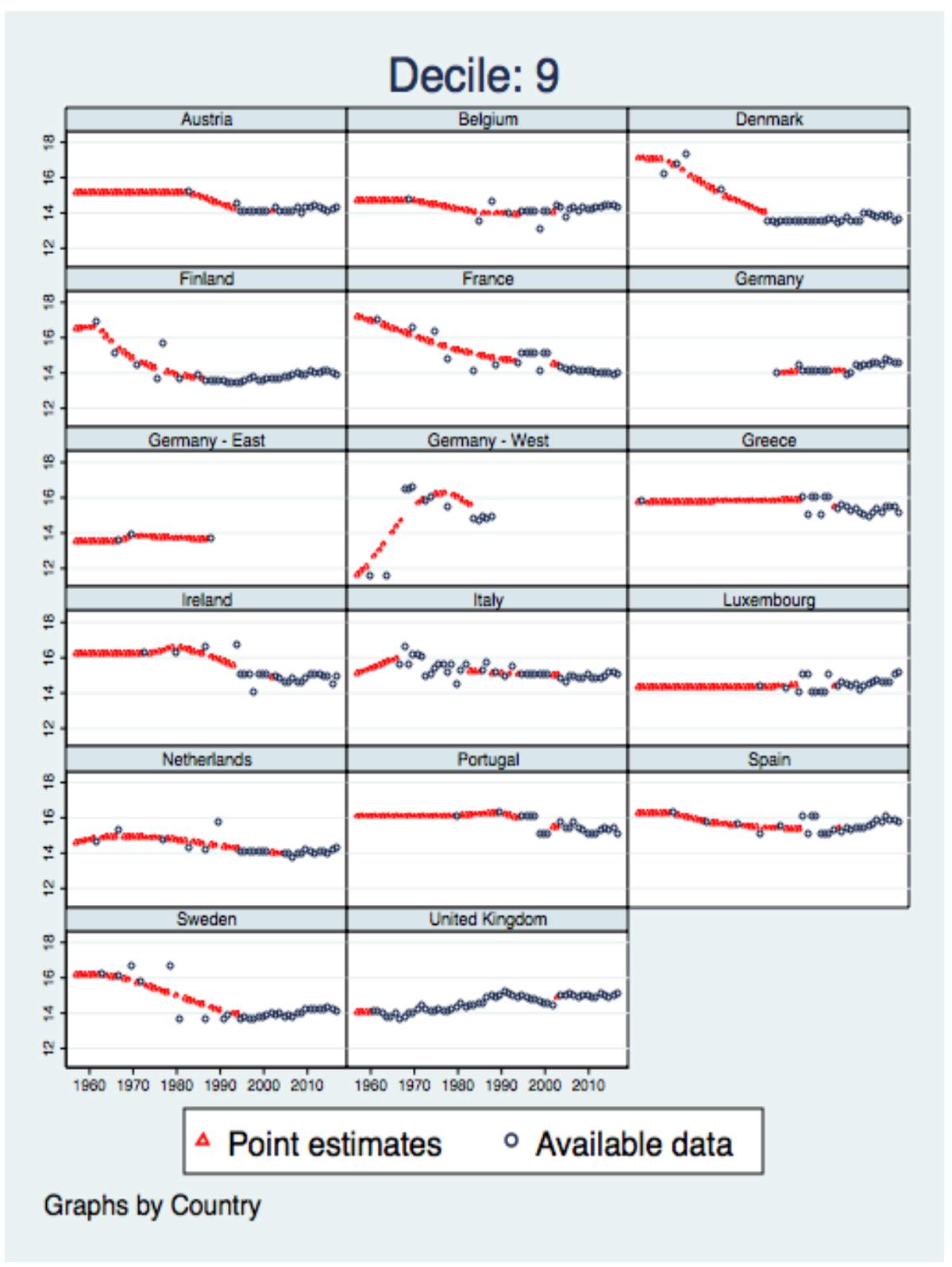


Figure 17: Available data on income shares and estimated values Tenth decile

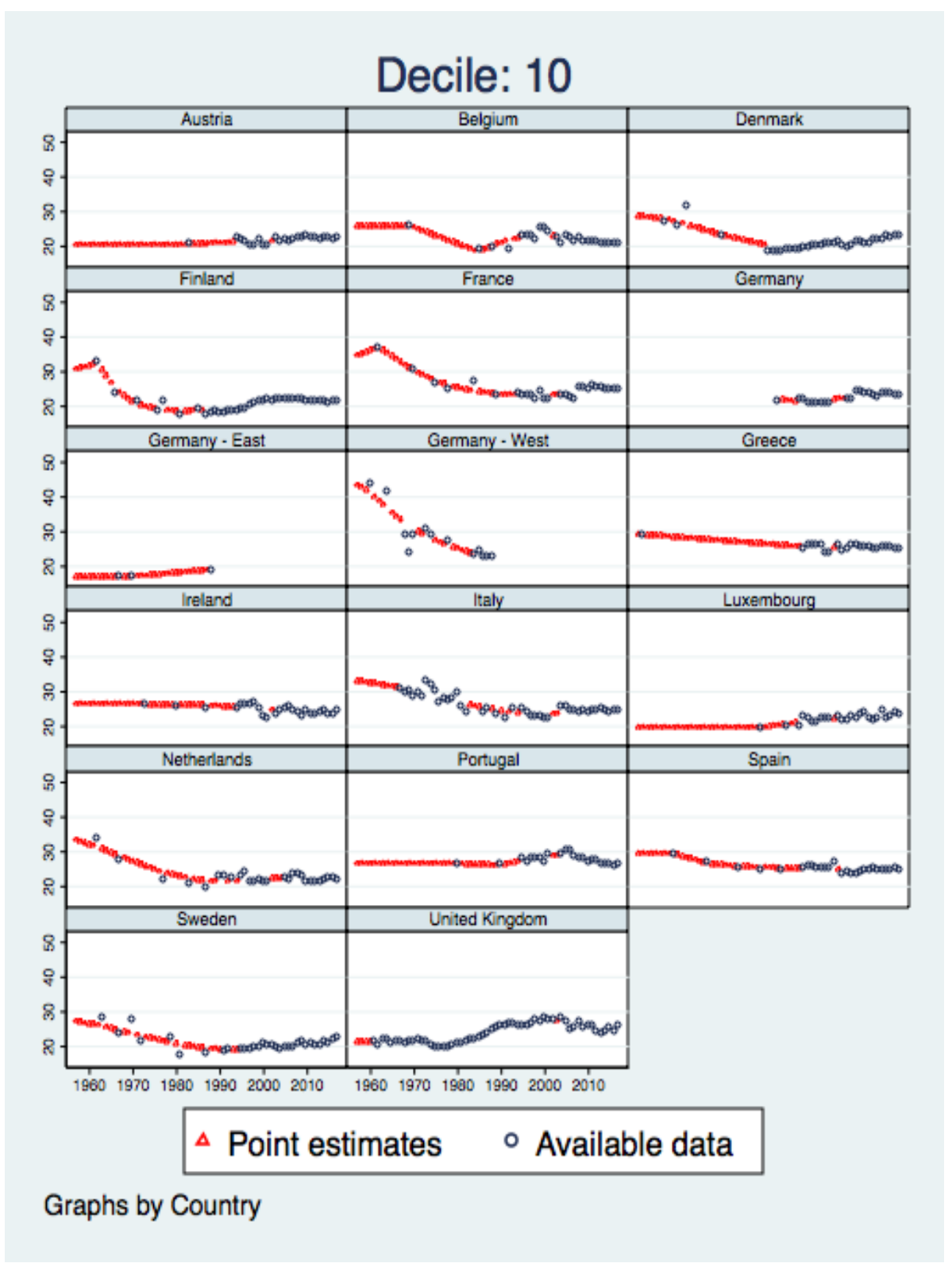




\section{References}

Alvaredo, F., Atkinson, A. B., Piketty, T., and Saez, E. (2012). The World Top Incomes Database. http://g-mond.parisschoolofeconomics.eu/topincomes.

Arts, W. and Gelissen, J. (2010). Models of the welfare state. In Castles, F., Leibfried, S., Lewis, J., Obinger, H., and Pierson, C., editors, The Oxford Handbook of the Welfare State. Oxford University Press, Oxford.

Atkinson, A. (1975). The Economics of Inequality. Oxford: Clarendon Press.

Atkinson, A. B., Piketty, T., and Saez, E. (2011). Top Incomes in the Long Run of History. Journal of Economic Literature, 49(1):3-71.

Blanchet, T., Chancel, L., and Gethin, A. (2019). How unequal is Europe? Evidence from distributional national accounts. WID.world Working Paper 2019/6, World Inequality Lab.

Bolt, J., Inklaar, R., de Jong, H., and Luiten van Zanden, J. (2018). Rebasing 'Maddison': new income comparisons and the shape of long-run economic development. Maddison Project Working Paper 10, Groningen Growth and Development Centre, University of Groningen.

Brandolini, A. (2007). Measurement of Income Distribution in Supranational Entities: the Case of the European Union. Temi di discussione (Economic working papers) 623, Bank of Italy, Economic Research Department.

Brandolini, A. and Rosolia, A. (2019). The distribution of well-being among Europeans. Questioni di Economia e Finanza (Occasional Papers) 496, Bank of Italy, Economic Research and International Relations Area.

Deaton, A. (2005). Measuring Poverty in a Growing World (or Measuring Growth in a Poor World). The Review of Economics and Statistics, 87(1):1-19.

Deininger, K. and Squire, L. (1996). A New Data Set Measuring Income Inequality. World Bank Economic Review, 10:3:565-91.

Esping-Andersen, G. (1990). The Three Worlds Of Welfare Capitalism. Princeton University Press, Princeton, New Jersey.

European Commission (2018). The EU Budget: Where Does the Money Go? http: //ec.europa.eu/budget/mff/index_en.cfm.

Ferrera, M. (2005). Welfare State Reform in Southern Europe: Fighting poverty and social exclusion in Italy, Spain, Portugal and Greece. Routledge, London.

Fredriksen, K. B. (2012). Income Inequality in the European Union. OECD Economics Department Working Papers 952, OECD. 
Goodman, A. and Shephard, A. (2002). Inequality and Living Standards in Great Britain: Some Facts, volume Briefing Notes No. 19. The Institute for Fiscal Studies.

Gough, I., Bradshaw, J., Ditch, J., Eardley, T., and Whiteford, P. (1997). Social assistance in OECD Countries. Journal of European Social Policy, 7:17-43.

Hong, S., Han, H., and Kim, C. (2019). World distribution of income for 19702010: dramatic reduction in world income inequality during the 2000s. Empirical Economics.

Jann, B. (2007). Univariate Kernel Density Estimation. ETH Zurich.

Milanovic, B. (2003). The Two Faces Of Globalization: Against Globalization As We Know It,. Development and Comp Systems.

Minoiu, C. (2007). Poverty Analysis based on Kernel Density Estimates from Grouped Data. Columbia University Institute of Social and Economic Research and Policy Working Papers, 07.

Minoiu, C. and Reddy, S. G. (2008). Kernel Density Estimation Based on Grouped Data: The Case of Poverty Assessment. IMF Working Papers, 183.

Pinkovskiy, M. and Sala-i-Martin, X. (2009). Parametric Estimations of the World Distribution of Income. NBER Working Papers 15433, National Bureau of Economic Research, Inc.

Sala-i-Martin, X. (2002). The World Distribution of Income (Estimated from Individual Country Distributions). Economics Working Papers 615, Department of Economics and Business, Universitat Pompeu Fabra.

Sala-i-Martin, X. (2006). The World Distribution of Income: Falling Poverty and... Convergence, Period. The Quarterly Journal of Economics, 121(2):351-397.

Schultz, T. P. (1998). Inequality in the Distribution of Personal Income in the World: How it is Changing and Why. Journal of Population Economics, pages 307-344.

Silverman, B. W. (1986). Density Estimation for Statistics and Data Analysis. Chapman \& Hall.

Social Situation Observatory (2012). http://www.socialsituation.eu/.

UNU/WIDER (2018). World Income Inequality Database (WIID 3.4). https:// www . wider . unu . edu/database/world-income-inequality-database-wiid34.

Wand, M. P. and Jones, M. (1995). Kernel Smoothing. Chapman \& Hall.

Yatchew, A. (2007). Nonparametric Regression Techniques in Economics. Journal of Economic Literature, 36 n. 2. 